\title{
Chromatin Central: towards the comparative proteome by accurate mapping of the yeast proteomic environment Anna Shevchenko*, Assen Roguev ${ }^{\dagger \neq}$, Daniel Schaft ${ }^{\dagger}$, Luke Buchanan ${ }^{\dagger}$, Bianca Habermann*, Cagri Sakalar ${ }^{\dagger}$, Henrik Thomas*, Nevan J Krogan, Andrej Shevchenko* and A Francis Stewart ${ }^{\ddagger}$
}

\begin{abstract}
Addresses: * MPI of Molecular Cell Biology and Genetics, Pfotenhauerstrasse 108, 01307 Dresden, Germany. ${ }^{\dagger}$ Genomics, BioInnovationsZentrum, Technische Universität Dresden, Am Tatzberg 47-51, 01307 Dresden, Germany. ${ }^{*}$ Department of Cellular and Molecular Pharmacology, University of California, San Francisco, 1700 4th Street, San Francisco, CA 94158, USA.
\end{abstract}

Correspondence: Andrej Shevchenko. Email: shevchenko@mpi-cbg.de. A Francis Stewart. Email: stewart@biotec.tu-dresden.de

Published: 28 November 2008

Genome Biology 2008, 9:RI67 (doi:I0.1 I86/gb-2008-9-II-r|67)

The electronic version of this article is the complete one and can be found online at http://genomebiology.com/2008/9/I I/RI67
Received: 29 July 2008

Revised: 21 October 2008

Accepted: 28 November 2008

(c) 2008 Shevchenko et al.; licensee BioMed Central Ltd.

This is an open access article distributed under the terms of the Creative Commons Attribution License (http://creativecommons.org/licenses/by/2.0), which permits unrestricted use, distribution, and reproduction in any medium, provided the original work is properly cited.

\begin{abstract}
Background: Understanding the design logic of living systems requires the understanding and comparison of proteomes. Proteomes define the commonalities between organisms more precisely than genomic sequences. Because uncertainties remain regarding the accuracy of proteomic data, several issues need to be resolved before comparative proteomics can be fruitful.

Results: The Saccharomyces cerevisiae proteome presents the highest quality proteomic data available. To evaluate the accuracy of these data, we intensively mapped a proteomic environment, termed 'Chromatin Central', which encompasses eight protein complexes, including the major histone acetyltransferases and deacetylases, interconnected by twelve proteomic hyperlinks. Using sequential tagging and a new method to eliminate background, we confirmed existing data but also uncovered new subunits and three new complexes, including ASTRA, which we suggest is a widely conserved aspect of telomeric maintenance, and two new variations of Rpd3 histone deacetylase complexes. We also examined the same environment in fission yeast and found a very similar architecture based on a scaffold of orthologues comprising about two-thirds of all proteins involved, whereas the remaining one-third is less constrained. Notably, most of the divergent hyperlinks were found to be due to gene duplications, hence providing a mechanism for the fixation of gene duplications in evolution.
\end{abstract}

Conclusions: We define several prerequisites for comparative proteomics and apply them to examine a proteomic environment in unprecedented detail. We suggest that high resolution mapping of proteomic environments will deliver the highest quality data for comparative proteomics. 


\section{Background}

Understanding the design logic of living systems is now mainly based on genomics and DNA sequence comparisons. Typically, protein comparisons are evaluated by sequence alignments. However, living systems run programs that are written both as passive information (the genome) and as dynamic, molecular ecologies (the proteome). This dichotomy drives proteomic research because no living system can be solely described by its DNA sequence. Accurate proteomic maps are logically the next dataset required to complement complete genome sequences. However, the generation of reliable proteomic data remains challenging [1-4].

The budding yeast, Saccharomyces cerevisiae, has led eukaryotic research in several fields, particularly genomics, reverse genetics, cell biology and proteomics. For proteomic mapping, $S$. cerevisiae has been the main venue for the evaluation of various methodologies, which led to the clear conclusion that biochemical methods based on physiological expression levels deliver the most accurate results. In contrast, bioinformatic, yeast two hybrid and overexpression approaches generate less accurate data that require validation by a different means [1-4].

In contrast to a genome sequence, it is unlikely that a proteomic map can ever be complete because proteomes change in response to alterations of cellular condition. Proteomes include a very large number of post-translational modifications that are inherently variable, as well as protein-protein interactions that vary over a wide range of stabilities. Nevertheless, a proteome is based on a stable core of protein complexes, which can be accurately mapped by biochemical approaches [2]. Hence, an accurate proteomic map will be based on the constellation of stable protein complexes for a given cellular condition. The map then provides a scaffold onto which transient interactions and post-translational modifications can be organized. Thereby, proteomes can be rationalized $[5,6]$.

The quest to understand proteomes has led to the definition of new perspectives and terms, such as a proteomic 'environment', which describes the local relationships within a group of interacting proteins; 'hubs', which is applied to proteins that interact with many other proteins [2]; and 'hyperlinks', which is a term we applied to proteins that are present in more than one stable protein complex [7]. Similarly, insight into proteomes can be gleaned from comparative proteomics [8]. However, without accurate proteomic maps, these new terms and perspectives, particularly those derived from comparative proteomics, have limited meaning.

To map the budding yeast proteome accurately, methodologies for physiological expression and purification of tagged proteins were developed based on gene targeting with the tandem affinity purification (TAP) tag [9,10]. The high throughput application of these methods by two different groups led to the best proteomic map datasets for any cell, whether prokaryotic or eukaryotic $[11,12]$. Collins et al. consolidated both datasets into one of even higher quality; nevertheless, they recommended more intensely focused data gathering to evaluate accuracy [13].

Here we address the issue of proteomic accuracy by intense exploration of a section of the budding yeast proteome that is related to chromatin regulation. Chromatin is regulated by multiprotein complexes, which dynamically target nucleosomes with a multitude of reversible modifications, such as acetylation, methylation, phosphorylation and ubiquitination (reviewed in [14]). Also, in budding yeast, many of these complexes have been individually isolated and functionally characterized, which provides a rich and detailed source of reference information. Previously, we concluded that greater accuracy can be attained by sequential tagging to reciprocally validate interactions $[10,15,16]$. Sequential tagging of candidate interactors to map a proteomic environment has also been termed proteomic navigation or SEAM (short for Sequential rounds of Epitope tagging, Affinity isolation and Mass spectrometry). For a low throughput approach, which also permits a more intense focus on individual experiments, sequential tagging will deliver improvements in accuracy.

Several other factors may reduce mapping accuracy. In the $S$. cerevisiae proteome every fourth protein is apparently a proteomic hyperlink [5]. That is, a member of more than one distinct protein complex. Hence, many pull-downs are mixtures of completely or partially co-purified complexes, together with other sub-stoichiometric and pair-wise interactors. Also, sorting out background proteins from genuine interactors remains challenging [5,17-19], especially when proteins are identified by mass spectrometric techniques with enhanced dynamic range, such as liquid chromatography tandem mass spectrometry (LC-MS/MS) or LC matrix-assisted laser desorption/ionization mass spectrometry (MALDI) MS/MS, which produce a large number of confident protein identifications in each pull-down. Furthermore, until recently, mass spectrometric identifications have mostly neglected the quantitative aspect. It was (and, largely, still is) difficult to determine which proteins are bona fide members of a tagged complex and, therefore, stoichiometric, and which interactors are sub-stoichiometric. Here we address these issues to develop refinements for improved accuracy of mapping, including working criteria to identify common background proteins and stoichiometric interactors.

Using the sequential strategy and these refinements, we mapped a large proteomic environment that we term 'Chromatin Central' because it includes eight protein complexes interconnected by hyperlinks encompassing the major histone aceytyltransferases and deacetylases in budding yeast. As evidence for mapping accuracy, we made several discoveries, including the identification of new subunits of known complexes and new complexes. 
To exploit the quality of the map for comparative proteomics, we then explored the same proteomic environment in the distantly related yeast Schizosaccharomyces pombe. This enabled a detailed comparison of two highly accurate proteomic environments to shed light on the evolution of proteomic architecture.

\section{Results \\ Establishing a proteomic environment}

Our approach to charting proteomic environments relies upon the sequential use of TAP and mass spectrometry to identify stable protein assemblies. In a typical TAP pull-down experiment, LC-MS/MS analysis identified over 500 proteins containing stoichiometric and transient bona fide protein interactors, along with a large number of background proteins of diverse origin and abundance. To dissect the composition of complexes, we employed a layered data mining approach. First, we sorted out common background proteins and then distinguished proteins specifically enriched in the TAP isolation using semi-quantitative estimates of their abundance (Figure 1).

\section{Common background proteins}

A list was established based on background proteins from proteins repetitively found in 20 diverse immunoaffinity purifications (IPs) that were selected from three unrelated projects, this project being one of those three. The other two were based on mitotic cell cycle regulation and vesicle transport. The tagged proteins and their known interactors, as well as ribosomal proteins, were first removed from the 20 primary IP lists. Then, of more than 2,00o proteins identified in these 20 IPs, 119 (Table S1 in Additional data file 1) were defined as common background because they were found at least once in each of the three independent projects. This list of 119 includes proteins with molecular weights ranging from 11 to $250 \mathrm{kDa}$ and expression levels of 100 to $10^{6}$ molecules per cell $[20,21]$. Most of these common background proteins were cytoplasmic [21-23], including heat shock, translation factors and abundant housekeeping enzymes. Once these common background proteins were removed from a particular IP list, it was further refined using abundance index (Aindex) filtering.

\section{Index of relative abundance}

The absolute amounts of immunoprecipitated protein varies between TAP purifications. However, within a purification, members of a stable protein complex should be isolated in approximately stoichiometric amounts and relatively enriched compared to the other detected proteins. Abundant background proteins are an exception; however, we always removed them from the list at the very beginning of the data processing routine as described above.

To estimate the relative abundance of individual proteins and hence obtain an additional means to distinguish genuine interactors from background, we used an arbitrary A-index. It was calculated as a ratio of the total number of MS/MS spectra acquired for a given protein (reported as 'matched queries' for each MASCOT hit) to the number of unique peptide sequences they matched. Essentially, the A-index is a relative measure of the amounts of co-isolated proteins from the gel. We applied it as a convenient way to distinguish bona fide subunits of the tagged complex from background proteins because they should be relatively enriched, compared to background. In a series of preliminary experiments, we observed that the A-index monotonously increased with increasing amount of loaded proteins from 50 to 800 fmols. When determined for six standard proteins of various molecular weights and properties, the A-index varied within a 50\% margin at any given protein loading (Figure $\mathrm{S} 1$ in Additional data file 2).

\section{Selecting genuine interactions to determine protein complexes}

Each protein complex was isolated several times within a round of IP experiments that used different baits $[10,15,16]$. Hence, several independent IPs established the protein complex composition or identified a hyperlink to another protein assembly (Figure S2 in Additional data file 2). In turn, proteins co-purified with a hyperlink and that did not belong to the complex characterized in the current round were selected as baits for the next sequential round. For $S$. cerevisiae, within five IP rounds, 21 out of 26 pull downs from unique baits were successful (for the full list of identified proteins, see Table S2 in Additional data file 1). After the ribosomal proteins were removed, a non-redundant list of proteins identified in all IPs, together with their A-indices, was assembled into a master table containing 1,301 proteins in total (Table $\mathrm{S} 3$ in Additional data file 1). Then we removed common background proteins and low abundant proteins whose A-indices were equal to 1 and were identified only once in the total of 21 IPs.

The common background proteins listed in the master table had an average A-index value of 1.4. We noticed that A-indices of more than $90 \%$ of background proteins were within $25 \%$ of the average, so we employed this empirical threshold to further sort out experiment-specific background. Since genuine interactors were supposed to be enriched in the IPs compared to background proteins, we introduced an arbitrary cut-off of 1.75 for A-indices of genuine protein interactions (Table $\mathrm{S}_{3}$ in Additional data file 1).

Proteins were recognized as stoichiometric core members of complexes if they did not belong to common background, were specifically enriched in corresponding IPs, and, most importantly, were co-isolated with baits within the corresponding round of sequential IPs (Figure 1). Potentially, these criteria might have eliminated some transient (yet genuine) interactors; however, we placed our priorities upon accuracy. Although the chosen 25\% margin might look arbitrary, the entire approach was validated by a good concordance of the 


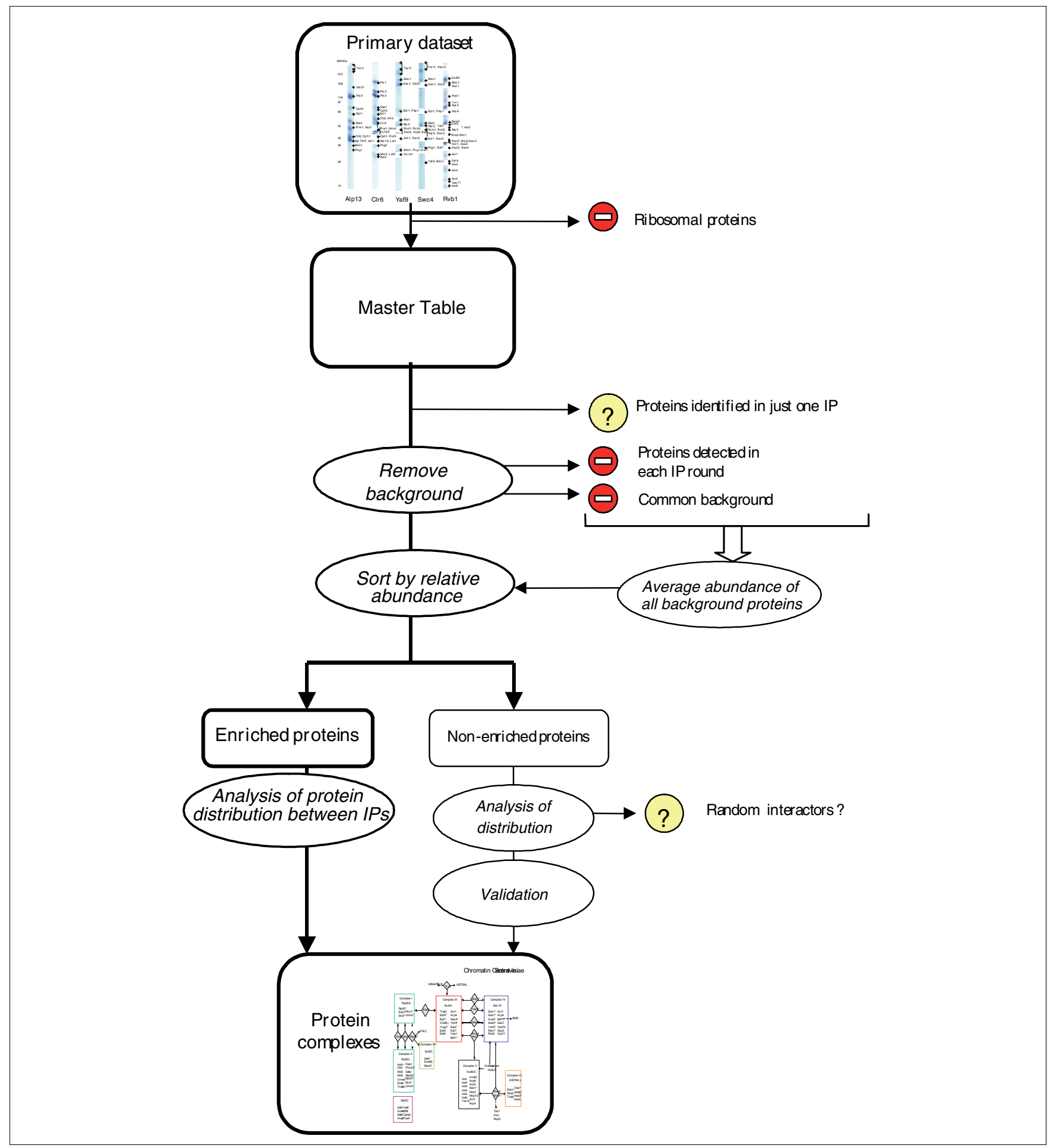

Figure I

Data processing workflow. The primary dataset is a complete list of proteins identified in IP experiments that were used to map the Chromatin Central proteomic environment in any of the two yeasts. After removal of ribosomal proteins, all hits together with their A-indices were compiled into a nonredundant master table and grouped according to IP rounds. To accurately determine the scaffold protein complexes, we further removed from the master table proteins having A-index = I that were identified only in one IP experiment and common background proteins. Using the average A-index of background proteins as a selection threshold, the remaining proteins were sorted into two large groups: proteins enriched in corresponding IP experiments and proteins whose abundance remained at the background level. Proteins in the first group were considered as genuine interactors and were assigned to complexes, assuming IP experiments in which they were identified. From the second group, only proteins that were validated by a reciprocal IP experiment were assigned to the corresponding complexes. 
composition of protein complexes in S. cerevisiae Chromatin Central with the published evidence, as described below.

\section{Chromatin Central in S. cerevisiae}

From 1,301 unique open reading frames (ORFs) in the master table, only 63 proteins (less than $5 \%$ of all identified proteins) matched the above selection criteria, comprising 9 stable protein complexes connected by 12 proteomic hyperlinks. Three out of these nine (ASTRA (for ASsembly of Tel, Rvb and Atmlike kinase), Snt2C and Sc_Rpd-LE (for Rpd3L expanded with Set3C core); Figure 2) are reported here for the first time, whereas the other six (complexes I-VI) have been characterized previously (note that the prefixes $\mathrm{Sc}$ _ and $\mathrm{Sp} \_$refer to proteins from $S$. cerevisiae and $S$. pombe, respectively; the suffix 'C' always refers to the protein complex).

Chromatin Central comprised four distinct protein assemblies, including: the histone deacetylase $\operatorname{Rpd} 3 p$ (Sc_Rpd3S, Sc_Rpd3L [24,25], Sc_Rpd-LE and Sc_Snt2C); at least two histone acetyltransferase complexes, Sc_NuA4 [26] and
SAGA/SLIK [27]; and two ATP-dependent chromatin remodeling complexes, Sc_Swr1C and Sc_Ino8oC [28,29]. The compositions of the individual protein complexes (Tables 1, 2, $3,4,5$ ) were compared with previous reports. Surprisingly, we found some discrepancies with data from the best proteome maps even though they were also obtained by TAP tagging $[11,12]$. In contrast, our results agree with several publications describing the biochemical and functional characterization of the individual complexes. In particular, complexes I, V and VI are identical to the previously reported Sc_Rpd3S, Sc_Swr1C and Sc_INO80C, respectively $[24,25,28,29]$.

In addition to the 12 known members of Sc_Rpd3L (complex II) $[24,25]$, we identified 2 novel subunits, including the 72 $\mathrm{kDa}$ protein Sc_Dot6p (ORF name YERo88C) and its $59 \mathrm{kDa}$ homolog Sc_Tod6p (Twin of the Dot6; ORF name YBL054W). Their sequences share 31\% identity; 46\% similarity and both possess the chromatin specific SANT domain [30]. Furthermore, the involvement of Sc_Dot6 in the regula-

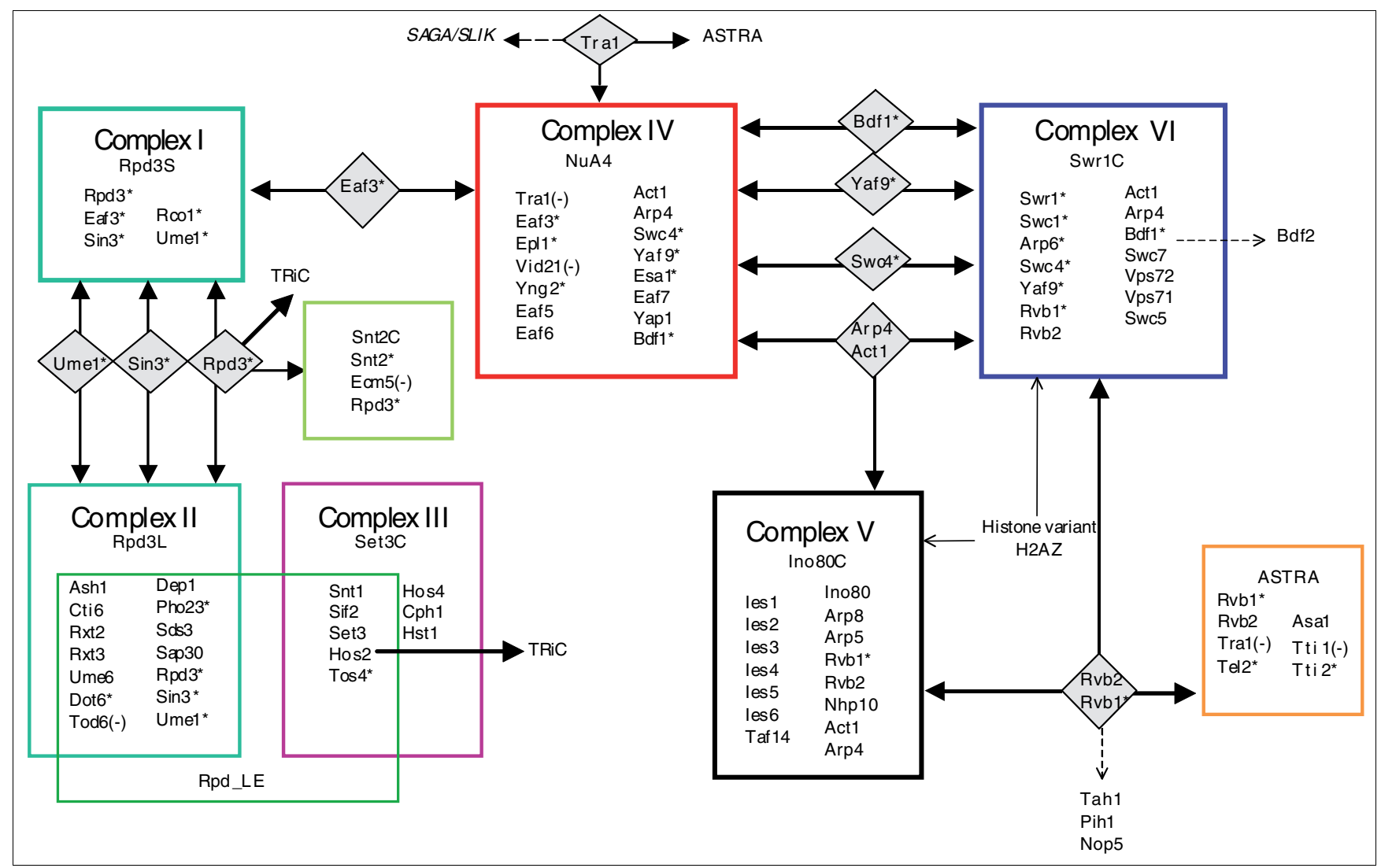

Figure 2

Chromatin Central proteomic environment in S. cerevisiae. Individual protein complexes are boxed; TAP-tagged subunits are indicated with asterisks. The proteomic hyperlinks (proteins shared between the individual complexes) are shown between the complexes in grey diamonds. The hyperlink from Tral to the SAGA/SLIK complex is designated with a dashed line/filled arrow because it was not identified in this work, but inferred from published evidence. Gene names designated with a minus (-) symbol indicate that their TAP tagging/immunoaffinity purification failed. Several relatively abundant (A-index $>$ 1.75) pair-wise interactors, also identified in proteome-wide screens [10I, I02], are mapped onto the scheme (dashed line/unfilled arrow). Set3C complex was previously characterized by TAP-tagging method in [10]. 
Table I

\begin{tabular}{|c|c|c|c|c|c|c|c|}
\hline \multicolumn{3}{|c|}{ S. cerevisiae } & \multicolumn{3}{|c|}{ S. pombe } & \multicolumn{2}{|c|}{ Sequence comparison } \\
\hline Gene name & ORF & $M W(k D a)$ & Gene name & ORF & $M W(k D a)$ & Identity/similarity (\%) & Orthologue \\
\hline TRAI & YHR099W & 433 & TRA2 & SPACIF5.IIC & 420 & $33 / 53$ & Gene duplication \\
\hline VID2I & YDR359C & 112 & VID2I & SPCCI795.08c & 112 & $23 / 40$ & \\
\hline EPLI & YFL024C & 97 & EPLI & SPCC830.05c & 65 & $36 / 51$ & \\
\hline ARP4 & YJL08IC & 55 & ALP5 & SPBP23A10.08 & 49 & $35 / 51$ & \\
\hline SWC4 & YGR002C & 55 & SWC4 & SPAC9GI.13c & 47 & $30 / 44$ & \\
\hline ESAI & YOR244W & 52 & MSTI & SPAC637.12c & 54 & $56 / 71$ & \\
\hline YAF9 & YNLI07W & 26 & YAF9 & SPACI7G8.07 & 25 & $45 / 64$ & \\
\hline ACTI & YFL039C & 42 & ACTI & SPBC $32 \mathrm{H} 8.12 \mathrm{c}$ & 42 & $90 / 97$ & \\
\hline EAF3 & YPR023C & 45 & $A L P / 3$ & SPAC23H4.I2 & 39 & $32 / 47$ & \\
\hline YNG2 & YHR090C & 32 & PNGI & SPAC3G9.08 & 31 & $32 / 53$ & \\
\hline EAF7 & YNLI36W & 49 & EAF7 & SPBCI6A3.19 & 31 & $22 / 43$ & \\
\hline YAPI & YML007W & 72 & PAPI & SPACI783.07c & 62 & $26 / 41$ & \\
\hline EAF5 & YELOI8W & 32 & & & & & No orthologues in S. pombe \\
\hline EAF6 & YJR082C & 13 & & & & & Predicted orthologue SPAC6F6.09 \\
\hline \multirow[t]{2}{*}{$B D F I$} & YLR399C & 77 & & & & & Predicted orthologue SPCCI 450.02 \\
\hline & & & $B D C I$ & SPBC2IDI0.10 & 34 & & No orthologues in S. cerevisiae \\
\hline
\end{tabular}

tion of telomere silencing has been indicated [31].

In addition to the 14 known members of Sc_NuA4 (complex IV) $[26,32]$, another new protein, the $72 \mathrm{kDa}$ Sc_Yap1p (ORF name YMLoo7W), which is a member of a family of fungal specific transcriptional activators, was identified as a subunit. Within Sc_Set3C (complex III) [10] we also identified a new member, the $55 \mathrm{kDa}$ protein Sc_Tos4p (ORF name YLR183C). It is a putative transcription factor of the forkhead family. Tagging Sc_Tos4p pulled down the entire Sc_Set3C, except for the hyperlink Sc_Hst1p [5] (also, see Figure S2 in Additional data file 2 and Table S2 in Additional data file 1).

We identified 12 proteomic hyperlinks in Chromatin Central (Figure 2). One of these proteins, the $422 \mathrm{kDa}$ Sc_Tra1p (ORF name YHRo99W) is a core member of Sc_NuA4 and SAGA/ SLIK [27], effectively also hyperlinking these two acetyltransferase complexes into Chromatin Central. Our attempts to TAP-tag Sc_Tra1p failed. However, Sc_Tra1p was co-purified when other Sc_NuA4 and also ASTRA subunits were sequentially tagged (Figure 2; also see Figure S2 in Additional data file 2 and Table S2 in Additional data file 1).

Notably, core-subunits of the histone deacetylase complex Sc_Set3C [10] were co-purified in sub-stoichiometric amounts with subunits of the Sc_Rpd3L complex (Table S2 in Additional data file 1).Sc_Set3C and Sc_Rpd3L complexes regulate overlapping target genes [33-35] and synthetic lethal screens have revealed genetic links between components of these complexes [36].
Altogether, the composition of individual complexes in Chromatin Central accords well with the published biochemical evidence. Furthermore, the sequential tagging approach revealed four novel subunits in three previously characterized complexes as well as three novel protein assemblies.

\section{Chromatin Central in S. pombe}

We next asked if the Chromatin Central environment is conserved between the distantly related fungi $S$. cerevisiae and $S$. pombe. In contrast to $S$. cerevisiae, no systematic biochemical isolation of protein complexes has yet been performed in $S$. pombe; however, complexes can be isolated with essentially the same TAP methodology with a similar success rate $[7,37]$. We exploited the architecture of Chromatin Central in $S$. cerevisiae to choose strategic baits for the work in $S$. pombe. The closest homologues of six $S$. cerevisiae hyperlinks (products of CLR6, ALP13, YAF9, SWC4, RVB1, TRA1 and TRA2 genes) were subjected to TAP tagging and immunoaffinity isolation, followed by mass spectrometric identification of corresponding interactors (Figure 3). For accuracy, we also isolated complexes associated with three more conserved subunits, encoded by PNG2, SWC2 and IES6. Thus, the characterization of each complex relied upon at least two independent TAP purifications targeting different baits.

As in the $S$. cerevisiae experiments, the identified proteins, together with their A-indices, were combined into a master table (Tables $\mathrm{S}_{2}$ and $\mathrm{S}_{4}$ in Additional data file 1). We also compiled a list of 250 common background proteins for $S$. pombe in the same way as we $\operatorname{did}$ for $S$. cerevisiae (Table $\mathrm{S} 1 \mathrm{in}$ 
Table 2

Members of histone deacetylase complexes of the Chromatin Central proteomic environments

\begin{tabular}{|c|c|c|c|c|c|c|c|c|}
\hline & \multicolumn{3}{|c|}{ S. cerevisiae } & \multicolumn{3}{|c|}{ S. pombe } & \multicolumn{2}{|c|}{ Sequence comparison } \\
\hline & Gene name & ORF & $M W(k D a)$ & Gene name & ORF & $\mathrm{MW}(\mathrm{kDa})$ & Identity/similarity (\%) & Orthologue \\
\hline Rpd3S/CIr6S & RPD3 & YNL330C & 49 & CLR6 & SPBC $36.05 C$ & 46 & $67 / 82$ & \\
\hline \multirow[t]{6}{*}{ complexes } & SIN3 & YOL004W & 175 & PST2 & SPAC23CII.I5 & 125 & $24 / 4 I$ & Gene duplication \\
\hline & RCOI & YMR075W & 79 & $\mathrm{CPH} 2$ & SPAC2F7.07c & 69 & $26 / 44$ & \\
\hline & RCOI & YMR075W & 79 & $\mathrm{CPHI}$ & SPACI6C9.05 & 45 & $25 / 42$ & Gene duplication \\
\hline & EAF3 & YPR023C & 45 & $A L P / 3$ & SPAC23H4.I2 & 39 & $32 / 47$ & \\
\hline & UMEI & YPLI39C & 51 & & & & & $\begin{array}{l}\text { Functional } \\
\text { orthologue of prwl }\end{array}$ \\
\hline & & & & PRWI & SPAC29A4.18 & 48 & & $\begin{array}{l}\text { Functional } \\
\text { orthologue of umel }\end{array}$ \\
\hline Rpd3L/Clr6L & RPD3 & YNL330C & 49 & CLR6 & SPBC $36.05 \mathrm{C}$ & 46 & $67 / 82$ & \\
\hline \multirow[t]{17}{*}{ complexes } & SIN3 & YOL004W & 175 & PSTI & SPBCI2C2.10C & $17 \mid$ & $32 / 49$ & \\
\hline & SIN3 & YOL004W & 175 & PST3 & SPBCI734.16C & 133 & $27 / 44$ & Gene duplication \\
\hline & CTI6 & YPLI8IW & 57 & CTI6 & SPBCI 685.08 & 46 & $28 / 44$ & \\
\hline & $\mathrm{PHO} 23$ & YNL097C & 37 & PNG2 & SPBCI709.1Ic & 35 & $29 / 45$ & \\
\hline & RXT3 & YDL076C & 34 & RXT3 & SPCCI 259.07 & 39 & $28 / 40$ & \\
\hline & $R \times T 2$ & YBR095C & 49 & $R \times T 2$ & SPBC 428.06c & 27 & & Figure S3 \\
\hline & SDS3 & YIL084C & 38 & SDS3 & SPAC25B8.02 & 31 & & \\
\hline & $D E P I$ & YALOI3W & 48 & $D E P I$ & SPBC 2 IC $3.02 \mathrm{c}$ & 55 & & Figure S3 \\
\hline & SAP3O & YMR263W & 23 & & & & & $\begin{array}{l}\text { No orthologues in S. } \\
\text { pombe }\end{array}$ \\
\hline & UME6 & YDR207C & 91 & & & & & $\begin{array}{l}\text { No orthologues in } S \text {. } \\
\text { pombe }\end{array}$ \\
\hline & DOT6 & YER088C & 72 & & & & & $\begin{array}{l}\text { No orthologues in } S \text {. } \\
\text { pombe }\end{array}$ \\
\hline & TOD6 & YBL054W & 59 & & & & & $\begin{array}{l}\text { No orthologues in } S \text {. } \\
\text { pombe }\end{array}$ \\
\hline & ASHI & YKLI85W & 66 & & & & & $\begin{array}{l}\text { No orthologues in } S \text {. } \\
\text { pombe }\end{array}$ \\
\hline & UMEI & YPLI39C & 51 & & & & & $\begin{array}{l}\text { Functional } \\
\text { orthologue of prwl }\end{array}$ \\
\hline & & & & PRWI & SPAC29A4.18 & 48 & & $\begin{array}{l}\text { Functional } \\
\text { orthologue of umel }\end{array}$ \\
\hline & & & & LAFI & SPACI $4 C 4.12 c$ & 34 & & $\begin{array}{l}\text { Predicted } \\
\text { orthologues } \\
\text { YAL034C* and } \\
\text { YOR338W }\end{array}$ \\
\hline & & & & LAF2 & SPCCI682.13 & 31 & & $\begin{array}{l}\text { Predicted } \\
\text { orthologues } \\
\text { YAL034C* and } \\
\text { YOR338W }\end{array}$ \\
\hline \multirow[t]{3}{*}{ Snt2 complex } & SNT2 & YGLI3IC & 163 & & & & & $\begin{array}{l}\text { Predicted orthologue } \\
\text { SPAC } 3 \mathrm{HI} .12 \mathrm{c}\end{array}$ \\
\hline & ECM5 & YMRI76W & 163 & & & & & $\begin{array}{l}\text { No orthologues in } S \text {. } \\
\text { pombe }\end{array}$ \\
\hline & RPD3 & YNL330C & 49 & & & & & SPBC $36.05 c$ \\
\hline
\end{tabular}


Table 2 (Continued)

\begin{tabular}{|c|c|c|c|c|c|c|c|c|}
\hline \multirow[t]{8}{*}{ Set3 Complex } & SNTI & YCR033W & 138 & SNTI & SPAC22EI2.19 & 75 & $25 / 44$ & \\
\hline & HOS2 & YGLI94C & 51 & HDAI & SPAC3G9.07c & 49 & $59 / 76$ & \\
\hline & SIF2 & YBRI03W & 59 & HIF2 & SPCCI 235.09 & 63 & $22 / 41$ & \\
\hline & SET3 & YKR029C & 85 & SET3 & SPAC22EI2.IIC & 95 & $24 / 42$ & \\
\hline & HOS4 & YILII2W & 124 & & & & & $\begin{array}{l}\text { No orthologues in } S \text {. } \\
\text { pombe }\end{array}$ \\
\hline & $\mathrm{CPHI}$ & YDRI55C & 17 & & & & & $\begin{array}{l}\text { Predicted orthologue } \\
\text { SPBC28F2.03* }\end{array}$ \\
\hline & HSTI & YOL068C & 58 & & & & & $\begin{array}{l}\text { Predicted orthologue } \\
\text { SPBCI6DI0.07c }\end{array}$ \\
\hline & TOS4 & YLRI83C & 55 & & & & & $\begin{array}{l}\text { Predicted orthologue } \\
\text { SPAPI4E8.02 }\end{array}$ \\
\hline
\end{tabular}

*Detected with related bait(s) as a minor component (Table S4 in Additional data file I).

Additional data file 1). Interestingly, the average A-index of common background proteins was almost identical in both yeasts (1.3 and 1.4 in the fission and budding yeasts, respectively), and, therefore, we used the same conservative threshold of 1.75 to define stoichiometric interactors.

Chromatin Central shows a very similar architecture in both yeasts (Figures 2 and 4). To assess the similarities more closely, we focused on orthologues, recognized by overall sequence similarity (best hits in forward and reciprocal BLAST searches) and similar composition of structural domains (Tables 1, 2, 3, 4, 5). Altogether, in both Chromatin Central environments we identified 47 pairs of confident orthologues and six pairs with marginal confidence (Figure $\mathrm{S}_{3}$ in Additional data file 2) out of a total of 139 proteins. For other $S$. cerevisiae and $S$. pombe proteins, BLAST searches identified no clear orthologous pairs (Tables 1, 2, 3, 4), although some of them might be functional orthologues (such as Sc_Ume1p and Sp_Prw1p).

More than half the subunits of Sc_Rpd3S and Sc_Rpd3L (complexes I and II) are orthologous to the members of corresponding S. pombe complexes Sp_Clr6S and Sp_Clr6L; however, we reveal (Figure 4 and Table 2) further similarities than previously documented [38]. In addition to the previously reported subunits, we identified Sp_Cti6p, Sp_Rxt2p, Sp_Rxt3p, Sp_Dep1p and Sp_Pst3p. Our study also revealed that Sp_Clr6L, like Rpd3L in the budding yeast, is hyperlinked to the NuA4 histone acetyltransferase complex via an MRG-family protein, Sp_Alp13p.

Complex IV (Sp_NuA4) comprises orthologues of the 12 core members of the Sc_NuA4 complex, including its catalytic subunit Sp_Mst1p (ORF name SPAC637.12c) [39-41] (Table 1). Complexes V and VI include the closest homologues of the $S$. cerevisiae ATP-dependent helicases Sc_Swr1p and Sc_Ino8op (ORF names SPAC11E3.01c and SPAC29B12.01, respectively), together with 20 subunits orthologous to members of Sc_Swr1C and Sc_Ino80C (Table 3). The correspond- ing chromatin remodeling complexes in $S$. cerevisiae catalyze replacement of histone $\mathrm{H} 2 \mathrm{~A}$ with its variant Htz1p $[29,42,43]$. Complexes V and VI in the fission yeast both associate with Sp_Pht1p, which is the $S$. pombe orthologue of Sc_Htz1p (Table S2 in Additional data file 1). Therefore, it is likely that these $S$. pombe complexes (now called Sp_Swr1C and Sp_Ino8oC) are also H2A.z chaperones.

Interestingly, while characterizing the composition of Sp_Ino8oC, we identified a $17 \mathrm{kDa}$ core subunit, whose gene has not been annotated as an ORF in the $S$. pombe genome (Figure $\mathrm{S}_{4}$ in Additional data file 2). The protein has no homologues within the Saccharomyces genus, yet possesses some remote similarity to a non-annotated genomic region in Schizosaccharomyces japonicus. We call this newly discovered S. pombe gene, IEC5 short for (Ino Eighty Complex subunit 5 [GenBank:FJ493251]).

Complex VI, ASTRA, is the same as the orthologous complex in $S$. cerevisiae except that the $S$. pombe genome encodes for two Tra1 homologues and only one, Tra1, is present in ASTRA (Table 4). The other, Tra2, is a subunit of Sp_NuA4 and presumably the $S$. pombe SAGA/SLIK complexes. In $S$. cerevisiae, the single Tra1 was found in all three complexes.

As we observed in $S$. cerevisiae for $\mathrm{Sc}$-Rpd3L, some Sp_Set3C subunits co-purified in sub-stoichiometric amounts with Sp_Clr6L and vice versa, when Sp_Set3p was used as bait (Table S2 in Additional data file 1). Notably, the three subunits (Sp_Snt1p,Sp_Hif2p, and Sp_Set3p) isolated together with Clr6L are the orthologues of the three (Sc_Snt2, Sc_Sif2, and Sc_Set3) isolated with Rpd3L. However, in contrast to the Sc_Set3C complex, which consists of eight subunits, the Sp_Set3C complex contains only four proteins (Table 2).

In a few instances we identified proteins with domains that are not present in the corresponding orthologous complexes in the other yeast, including Sp_Msc1p (ORF name 
Table 3

\begin{tabular}{|c|c|c|c|c|c|c|c|c|}
\hline & \multicolumn{3}{|c|}{ S. cerevisiae } & \multicolumn{3}{|c|}{ S. pombe } & \multicolumn{2}{|c|}{ Sequence comparison } \\
\hline & Gene name & ORF & $M W(k D a)$ & Gene name & ORF & $M W(k D a)$ & Identity/similarity (\%) & Orthologue \\
\hline Swrl & SWRI & YDR334W & 174 & SWRI & SPACIIE3.0IC & 149 & $43 / 60$ & \\
\hline \multirow[t]{15}{*}{ complex } & SWC2 & YDR485C & 90 & SWC2 & SPBP35G2.I3C & 36 & $24 / 45$ & \\
\hline & $B D F I$ & YLR399C & 77 & $B D F I$ & SPCCI 450.02 & 65 & $30 / 50$ & \\
\hline & SWC4 & YGR002C & 55 & SWC4 & SPAC9GI.I3c & 47 & $30 / 44$ & \\
\hline & ARP4 & YJL08IC & 53 & ALP5 & SPBP23AI 0.08 & 49 & $35 / 51$ & \\
\hline & $R V B I$ & YDRI90C & 50 & $R V B I$ & SPAPB8E5.09 & 50 & $70 / 84$ & \\
\hline & RVB2 & YPL235W & 51 & RVB2 & SPBC83.08 & 51 & $70 / 86$ & \\
\hline & ARP6 & YLR085C & 50 & ARP6 & SPCC550.12 & 45 & $32 / 50$ & \\
\hline & SWC5 & YBR23IC & 34 & SWC5 & SPCC576.13 & 25 & $25 / 49$ & \\
\hline & VPS7I & YML04IC & 30 & VPS7I & SPBC29A3.05 & 16 & $30 / 45$ & \\
\hline & YAF9 & YNLI07W & 26 & YAF9 & SPACI7G8.07 & 25 & $45 / 64$ & \\
\hline & $A C T I$ & YFL039C & 42 & $A C T I$ & $\mathrm{SPBC} 32 \mathrm{H} 8.12 \mathrm{c}$ & 42 & $90 / 97$ & \\
\hline & HTZI & YOLOI2C & 14 & PHTI & SPBCIIBI0.10c & 19 & $70 / 81$ & \\
\hline & SWC3 & YALOIIw & 73 & SWC3 & SPAC $4 \mathrm{H} 3.02 \mathrm{c}$ & 45 & & Figure S3 \\
\hline & SWC7 & YLR385c & 15 & & & & & $\begin{array}{l}\text { No orthologues in S. } \\
\text { pombe }\end{array}$ \\
\hline & & & & $\mathrm{MSCl}$ & SPAC343.IIC & 180 & & $\begin{array}{l}\text { No orthologues in } \mathrm{S} \text {. } \\
\text { cerevisiae }\end{array}$ \\
\hline INO80 & INO80 & YGLI50C & $17 \mid$ & INO80 & SPAC29BI2.0I & 183 & $45 / 60$ & \\
\hline \multirow[t]{19}{*}{ complex } & ARP8 & YORI4IC & 100 & ARP8 & SPAC $664.02 \mathrm{c}$ & 70 & $29 / 48$ & \\
\hline & ARP5 & YNL059C & 88 & ARP5 & SPBC 365.10 & 82 & $39 / 61$ & \\
\hline & $R V B I$ & YDRI90C & 50 & $R V B I$ & SPAPB8E5.09 & 50 & $70 / 84$ & \\
\hline & $R V B 2$ & YPL235W & 51 & RVB2 & SPBC83.08 & 51 & $70 / 86$ & \\
\hline & ARP4 & YJL08IC & 53 & ALP5 & SPBP23AI 0.08 & 49 & $35 / 51$ & \\
\hline & HTZI & YOLOI2C & 14 & PHTI & SPBCIIBI0.10c & 19 & $70 / 81$ & \\
\hline & IES6 & YEL044W & 19 & IES6 & SPAC222.04c & 13 & $40 / 55$ & \\
\hline & IES2 & YNL2I5W & 36 & IES2 & SPAC6BI $2.05 \mathrm{c}$ & 34 & & Figure S3 \\
\hline & IES4 & YORI89W & 13 & IES4 & SPAC23G3.04 & 21 & & Figure S3 \\
\hline & $A C T I$ & YFL039C & 42 & $A C T I$ & $\mathrm{SPBC} 32 \mathrm{H} 8.12 \mathrm{c}$ & 42 & $90 / 97$ & \\
\hline & TAFI4 & YPLI29w & 27 & & & & & $\begin{array}{l}\text { Predicted orthologue } \\
\text { SPAC } 22 \mathrm{HI} 2.02^{*}\end{array}$ \\
\hline & $|E S|$ & YFLOI3C & 79 & & & & & $\begin{array}{l}\text { No orthologues in } S \text {. } \\
\text { pombe }\end{array}$ \\
\hline & IES3 & YLR052W & 28 & & & & & $\begin{array}{l}\text { No orthologues in } S \text {. } \\
\text { pombe }\end{array}$ \\
\hline & IES5 & YER092W & 14 & & & & & $\begin{array}{l}\text { No orthologues in } S \text {. } \\
\text { pombe }\end{array}$ \\
\hline & NHPIO & YDL002C & 24 & & & & & $\begin{array}{l}\text { Predicted orthologues } \\
\text { SPBC28F2.1I and } \\
\text { SPAC57A10.09c }\end{array}$ \\
\hline & & & & NHTI & SPACI0F6.08c & 38 & & $\begin{array}{l}\text { No orthologues in } \mathrm{S} \text {. } \\
\text { cerevisiae }\end{array}$ \\
\hline & & & & $|E C|$ & SPACI 44.02 & 28 & & $\begin{array}{l}\text { No orthologues in } \mathrm{S} \text {. } \\
\text { cerevisiae }\end{array}$ \\
\hline & & & & IEC3 & SPCCI 259.04 & 18 & & $\begin{array}{l}\text { No orthologues in S. } \\
\text { cerevisiae }\end{array}$ \\
\hline & & & & IEC5 & $\begin{array}{l}\text { New sequence, } \\
{[\text { [GenBank:FJ49325I] }}\end{array}$ & 17 & & $\begin{array}{l}\text { No orthologues in } S \text {. } \\
\text { cerevisiae }\end{array}$ \\
\hline
\end{tabular}

\footnotetext{
*Detected with related bait(s) as a minor component (Table S4 in Additional data file I).
} 
Table 4

\begin{tabular}{|c|c|c|c|c|c|c|c|}
\hline \multicolumn{3}{|c|}{ S. cerevisiae } & \multicolumn{3}{|c|}{ S. pombe } & \multicolumn{2}{|c|}{ Sequence comparison } \\
\hline Gene name & ORF & $\mathrm{MW}(\mathrm{kDa})$ & Gene name & ORF & $M W(k D a)$ & Identity/similarity (\%) & Orthologue \\
\hline TRAI & YHR099W & 433 & TRAI & SPBPI6F5.03c & 422 & $34 / 54$ & \\
\hline TTII & YKL033W & 119 & TTII & SPCC622.13c & 125 & $21 / 41$ & \\
\hline TEL2 & YGR099W & 79 & TEL2 & SPAC458.03 & 99 & $23 / 43$ & \\
\hline RVBI & YDRI90C & 50 & RVBI & SPAPB8E5.09 & 50 & $70 / 84$ & \\
\hline RVB2 & YPL235W & 51 & RVB2 & SPBC83.08 & 51 & $70 / 86$ & \\
\hline TTI2 & YJRI36C & 49 & TTI2 & SPBCI604.17c & 53 & $23 / 46$ & \\
\hline ASAI & YPR085c & 51 & ASAI & SPACI006.02 & 41 & & Figure S3 \\
\hline
\end{tabular}

SPAC343.11c), which is a member of the Sp_Swr1C complex. The function of this protein is not known, although Ahmed et al. [44] suggested that Msc1 is involved in chromatin regulation and DNA damage response. Msc1 contains a remarkable composition of domains, including three PHD fingers [45], PLU-1 [46], zf-C5HC2, JmjC and JmjN [47]. It was recently shown that the Msc1 PHD fingers act as an E3 ubiquitin ligase [48], while in other proteins the JmjC domain mediates histone demethylation [49]. None of the Sc_Swr1C subunits possess these domains or appears to be remotely similar to Sp_Msc1 (Table $\mathrm{S}_{5}$ in Additional data file 2).
We identified nine hyperlinks within Chromatin Central in $S$. pombe, all of which are orthologues to corresponding proteins in the budding yeast. As our attempts to purify TRA2 failed (as they did in S. cerevisiae), it remains unclear if, similar to the budding yeast, this protein is also shared between Sp_NuA4 and an assembly orthologous to SAGA/SLIK [50].

\section{Independent validation of functional relationships within Set3C and Swr IC complexes}

We independently validated some of the novel proteomics

Table 5

\begin{tabular}{|c|c|c|c|c|c|c|c|}
\hline & \multicolumn{3}{|c|}{ S. cerevisiae } & \multicolumn{3}{|c|}{ S. pombe } & \multirow{2}{*}{$\frac{\text { Sequence comparison }}{\text { Identity/similarity (\%) }}$} \\
\hline & Gene name & ORF & $M W(k D a)$ & Gene name & ORF & $M W(k D a)$ & \\
\hline \multirow{8}{*}{$\begin{array}{l}\text { TriC chaperonin-containing } \\
\text { complexes }\end{array}$} & CCTI & YDR2I2w & 60 & CCTI & SPBCI2D 12.03 & 60 & $77 / 89$ \\
\hline & CCT2 & YILI42w & 57 & $\mathrm{CCT} 2$ & SPACID4.04 & 57 & $69 / 83$ \\
\hline & ССT3 & YJLOI4W & 59 & CCT3 & SPBCIA4.08c & 58 & $69 / 83$ \\
\hline & CCT4 & YDLI43w & 58 & CCT4 & SPBCI06.06 & 57 & $67 / 83$ \\
\hline & CCT5 & YJR064W & 62 & CCT5 & SPACI $420.02 c$ & 59 & $64 / 82$ \\
\hline & CCT6 & YDRI88w & 60 & CCT6 & SPBC646.1I & 59 & $60 / 76$ \\
\hline & CCT7 & YJLIIIW & 60 & CCT7 & $\mathrm{SPBC} 25 \mathrm{H} 2.12 \mathrm{c}$ & 61 & $68 / 83$ \\
\hline & ССТ8 & YJL008c & 62 & ССТ8 & SPBC $337.05 c$ & 60 & $53 / 73$ \\
\hline \multirow{8}{*}{$\begin{array}{l}\text { Selected stoichiometric pair-wise } \\
\text { Interactors* }\end{array}$} & BDF2 & YDL070W & 72 & & & & \\
\hline & $\mathrm{PIHI}$ & YHR034C & 40 & & & & \\
\hline & TAHI & YCR060W & 12 & & & & \\
\hline & NOP5 & YOR3IOC & 60 & NOP5 & SPAC23G3.06 & 57 & \\
\hline & & & & NAPII & SPCC364.06 & 44 & \\
\hline & & & & NAPI 2 & SPBC2DI0.IIC & 43 & \\
\hline & & & & KAPII 4 & SPAC22HI $0.03 c$ & 111 & \\
\hline & & & & CBF5 & SPAC29A4.04C & 53 & \\
\hline
\end{tabular}

*Corroborates previous publications $[13,42,101,102]$. 


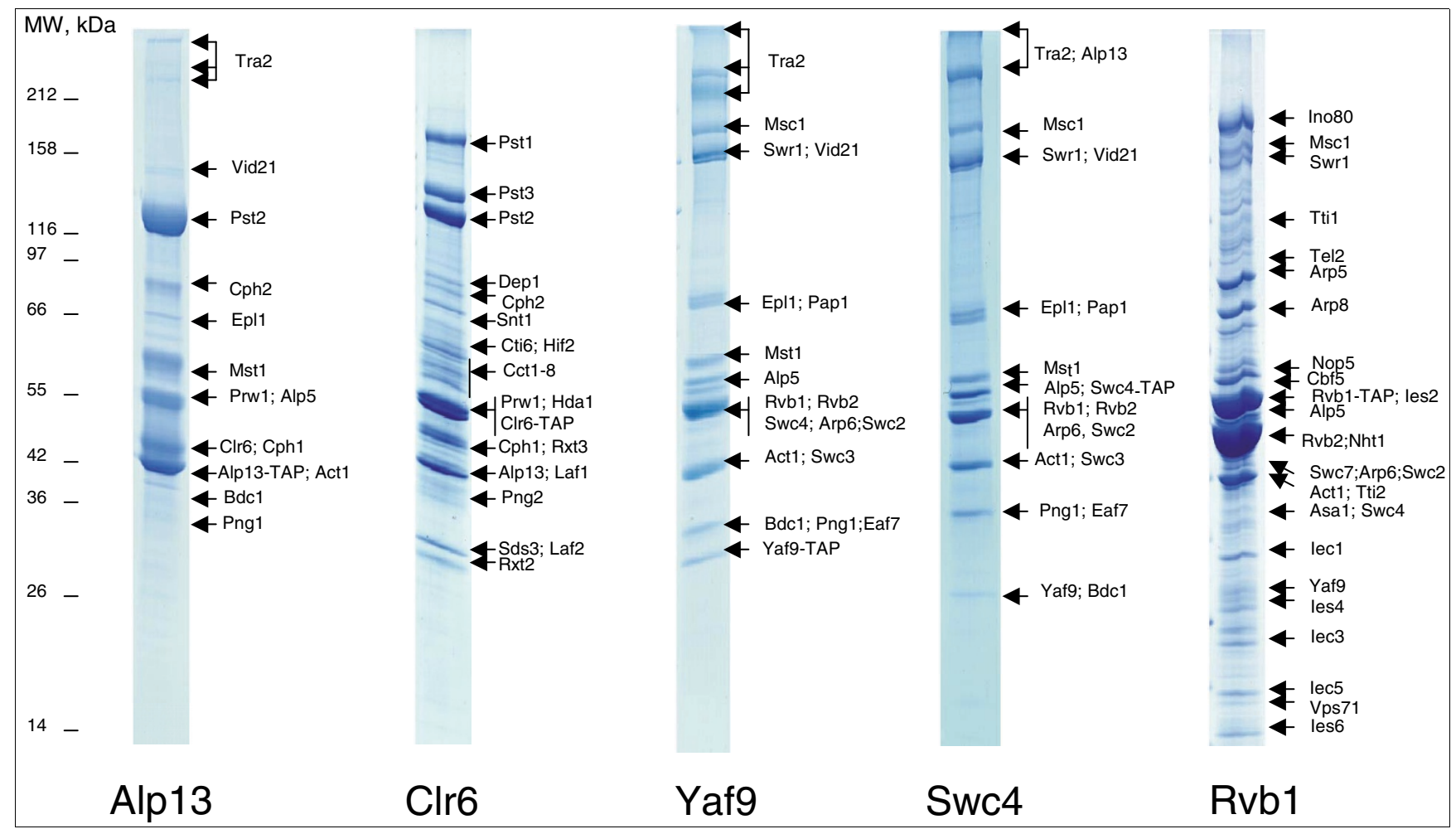

Figure 3

Representative Coomassie stained polyacrylamide gels of immunoaffinity isolations used for deciphering the Chromatin Central environment in S. pombe. These baits were selected for IP experiments as plausible proteomic hyperlinks. Bands, in which corresponding proteins were identified by mass spectrometry, are indicated with arrows for each lane. The full list of identified proteins is presented in Table S4 in Additional data file I.

observations, namely the insights regarding Set3C and Swr1C, using quantitative genetic interaction data from $S$. cerevisiae [51] and $S$. pombe [52,53].

Our proteomic data suggest that Set3C contains a conserved core complex of four proteins (Set3, Hos2, Snt1, and Sif2) and physically interacts with Rpd3L in both $S$. cerevisiae and $S$. pombe. To validate these findings, we compared the correlation coefficients of genetic profiles of the two Set3C core components in both yeasts (Sc_Set3 and Sc_Hos2; Sp_Set3 and Sp_Hda1) against genetic profiles of a set of 239 direct homologs in the two species. As expected, the correlation between the two core members (Set3 and Hos2) and Sif2, is well beyond the 9oth percentile (Figure $5 \mathrm{a}$ ), suggesting they act in concert. In contrast Hst1, also a subunit of Sc_Set3C, shows a much lower correlation, which is consistent with its absence from the core complex (as was previously shown for Sc_Hst1 [10]) or not being a part of the complex at all (Sp_Hst1). Furthermore, correlation of the Set3C core with the Sc_Rpd3L subunit Sp_Pho23 (Sp_Png2) is also high in both yeasts and higher than the correlation with one of the Rpd3S subunits (Rco1, Sp_Cph1). The functional division within Sc_Set3C becomes even more obvious when examining individual interactions of Set3C core and extension subunits. Members of the Set $3 \mathrm{C}$ core display stronger positive genetic interactions with each other, compared to the
Set3C extension subunits, and their genetic interaction patterns differ from patterns of Swr1C, SAGA and Prefoldin members (Figure 5b). Taken together, these data provide genetic evidence that Sc_Set3C encompasses two functional modules, one of which (Set3C core) interacts closely with $\mathrm{Rpd} 3 \mathrm{~L}$. This functional evidence corroborates our proteomic mapping data, suggesting that the Set $3 \mathrm{C}$ complex in S. pombe is only represented by core subunits, while the orthologous complex in $S$. cerevisiae has an extension of four extra subunits. In both yeasts, the core Set3C interacts with $\operatorname{Rpd} 3 \mathrm{~L}$ to form a distinct module referred to as Rpd3LE.

In $S$. pombe another complex, Swr1C, contains a newly identified subunit, Msc1. Its closest homolog in Sc_Ecm5 is not a part of Swr1C in budding yeast. To independently validate this finding, we examined and compared individual genetic interactions of seven of the Swr1C subunits in both yeasts with the genetic patterns of Sp_Msc1 (Sc_Ecm5). Consistent with our proteomic data, Sp_Msc1, unlike Sc_Ecm5, shows strong positive genetic interactions and a very similar pattern to the other members of the complex (Figure $5 \mathrm{c}$ ). Hence, pairs of genetic profiles containing Sc_Ecm5/Sp_Msc1 and other members of Swr1C show weak correlation in $S$. cerevisiae, but strong correlation in $S$. pombe (Figure $5 \mathrm{~d}$ ). Taken together, these genetic data confirm our proteomic mapping observations. 


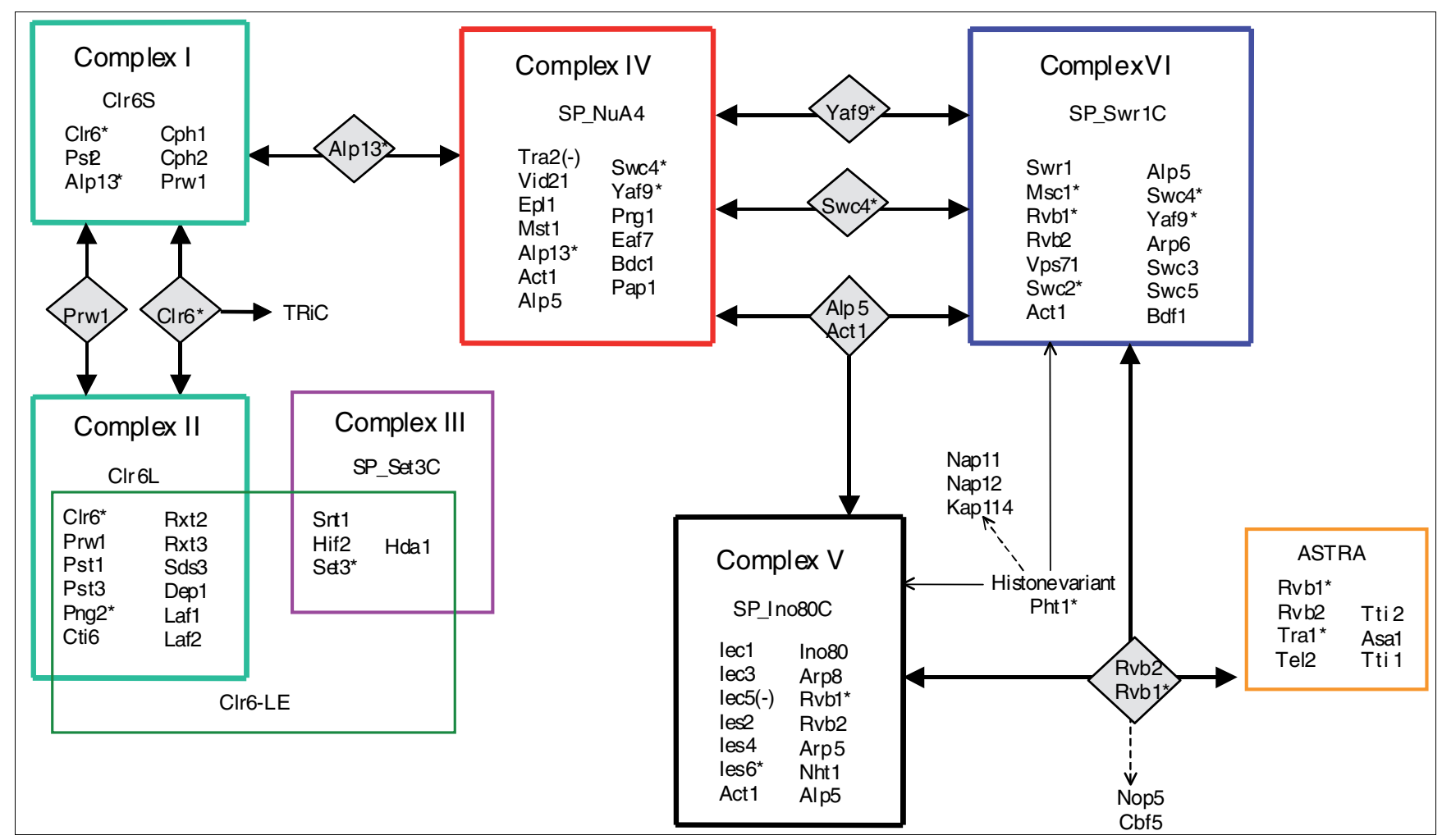

Figure 4

Chromatin Central proteomic environment in S. pombe. Individual protein complexes are boxed; color coding designates the protein complexes that are orthologous to the corresponding complexes in S. cerevisiae as shown in Figure 2. TAP-tagged subunits are designated by asterisks; minus (-) signs indicate that the IP experiment failed; proteomic hyperlinks are shown between the complexes in grey diamonds. Certain confident pair-wise interactors, discussed in the text, are designated with dashed arrows.

\section{Discussion}

By navigating a complex proteomic environment in two divergent yeasts with high accuracy, we obtained a new level of precise insight into the comparative proteome and also extracted several new and subtle discoveries.

\section{Comparative profile of a proteomic environment}

The overall architecture of Chromatin Central is the same in the two yeasts; however, there is a surprising amount of variation in their subunit composition. For both yeasts, Chromatin Central is based on the same eight complexes, encompassing 53 orthologous protein pairs plus a further 33 proteins that appear to be species specific (23 in S. cerevisiae, 10 in $S$. pombe). Of these 33 , three pairs have a very similar composition of functional domains (Table $\mathrm{S}_{5}$ in Additional data file 2). Hence, a very similar architecture is sustained by a scaffold based on about two-thirds of all the proteins involved, whereas the remaining one-third appears to be less constrained.

Analyses of domain composition (Table $\mathrm{S}_{5}$ in Additional data file 2) revealed that many subunits (19 in S. cerevisiae and 21 in $S$. pombe) possess bromo-, chromo-, SANT or PHD finger domains, which can bind either methylated or acetylated histones or other chromatin determinants [30,54-57], thus potentially targeting their complexes to specific regions of chromatin. Along with the seven enzymes in Chromatin Central, these putative targeting subunits are the most highly conserved subunits between the two yeasts. For example, Sc_NuA4 and Sp_NuA4 complexes retain all four targeting factors: the PHD fingers of Sc_Yng2/Sp_Png2; the bromodomains of Sc_Bdf1/Sp_Bdc1 and the chromodomains of Sc_Eaf3/Sp_Alp13 and Sc_Esa1/Sp_Mst1. Similarly, the different PHD finger subunits of $\operatorname{Rpd}_{3} S$ and $\mathrm{Rpd} 3 \mathrm{~L}$ (Sc_Rco1 and Sp_Cph2 in Rpd3S/Clr6S; Sc_Cti6 and Sp_Cti6 as well as Sc_Pho23 and Sp_Png2 in Rpd3L/Clr6L), which appear to direct these complexes to differentially methylated nucleosomes [58], are conserved. Hence, almost half of the conserved scaffold of Chromatin Central is based on proteins that convey the functions of the environment, that is, the reading and writing of the histone code.

\section{Comparative proteomics and proteomic hyperlinks}

In contrast to the conserved scaffold of Chromatin Central, the proteomic hyperlinks appear to be less constrained. We define proteomic hyperlinks, which are notable features of 
(a)

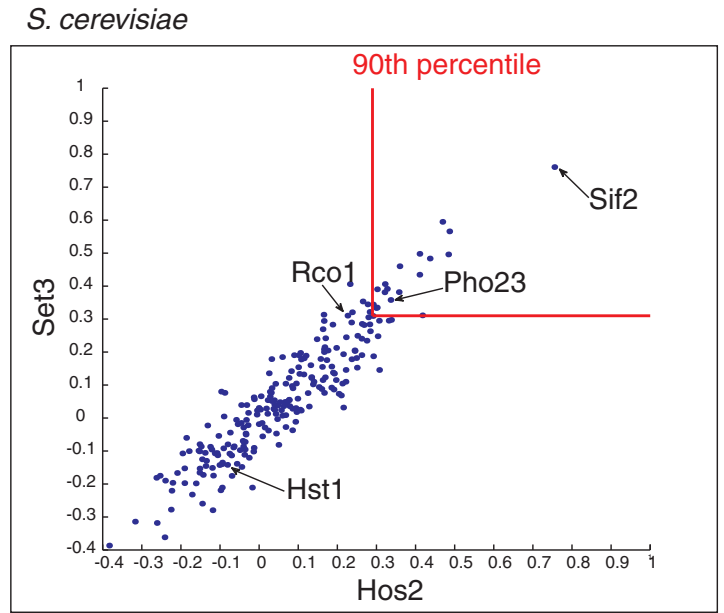

\section{S. pombe}

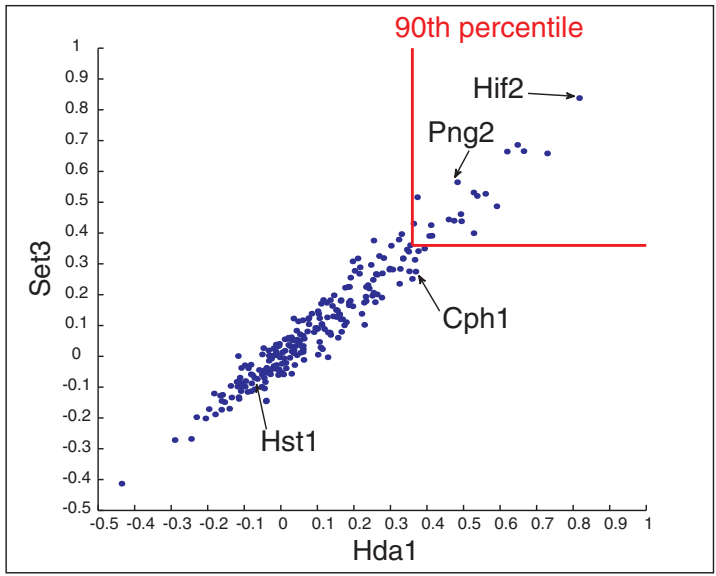

(b)

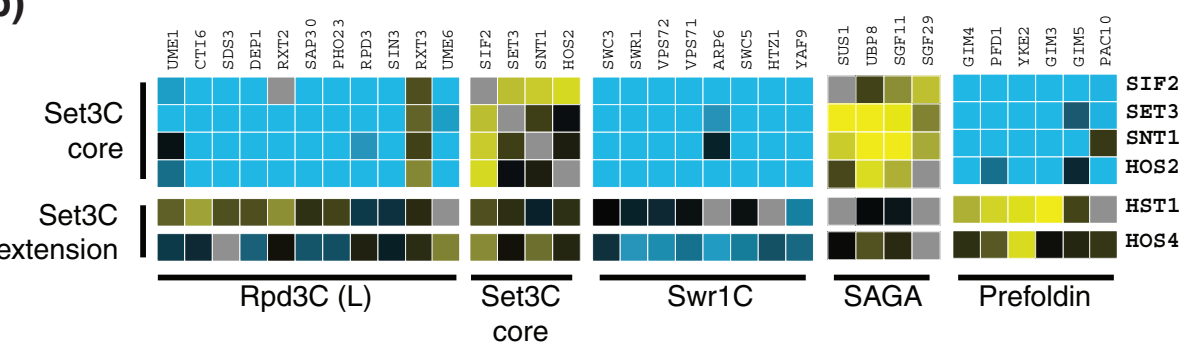

(c)
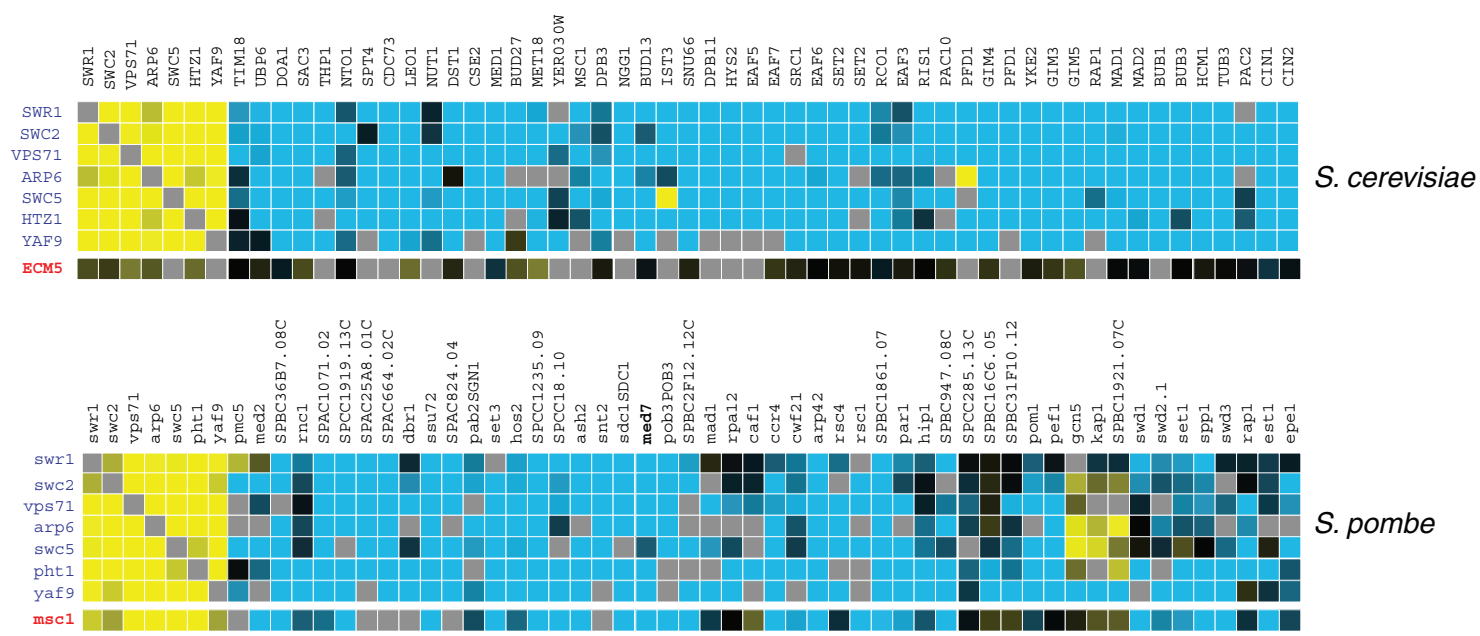

(d)

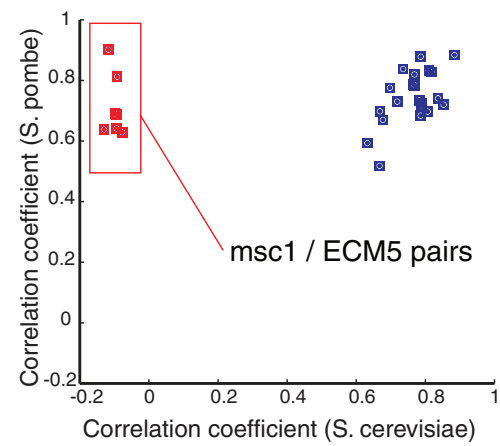

$<\begin{array}{ccccccc}-3 & -2 & -1 & 0 & 1 & 2 & >\end{array}$

interaction magnitude

Figure 5 (see legend on following page) 


\begin{abstract}
Figure 5 (continued)
Genetic interactions support the proteomic observations. (a) Scatter plots of correlation coefficients between genetic profiles for the two Set $3 \mathrm{C}$ subunits, Set3 and Hos2, in S. cerevisiae and S. pombe across 239 direct homologs between the two species. In both species Sif2 (Hif2) is highly correlated with both Set3 and Hos2, consistent with its being a subunit of the core Set3C, whilst Hst (part of the Sc_Set3C extension) is uncorrelated with either Set3 or Hos2. Pho23 (Png2), a subunit of Rpd3C(L), correlates better with Set3 and Hos2 than does Rcol (CphI), a subunit of Rpd3C(S). The 90th percentile of the data is indicated. (b) Subunits of the core Set3C and Set3C extension show different genetic interaction patterns. Shown are genetic interactions between Set3C core and extension subunits and Swr IC, SAGA and Prefoldin subunits. Color-coding of the interaction magnitude (shown in the key) is as follows: shades of cyan indicate synthetic sick/lethal (negative) interactions typically observed between genes acting on parallel pathways; shades of yellow represent suppressive (positive) interactions seen primarily between genes acting on the same pathway and within stable protein complexes. (c) Mscl in $S$. pombe is a member of SwrIC, while its S. cerevisiae ortholog $(\mathrm{Ecm} 5)$ is not. Genetic profiles of members of the complex in the two species are shown with $\mathrm{Mscl}$ and Ecm5 profiles aligned at the bottom. Genetic pattern of $\mathrm{Mscl}$ is very similar to the rest of the complex and positive genetic interactions with the other members indicate that it is a bona fide member of SwrIC in S. pombe. Color-coding is as for (b). (d) A scatter plot of pair-wise correlation coefficients of genetic profiles of members of SwrIC in S. cerevisiae and S. pombe. Consistent with (c), data-points corresponding to pairs containing Mscl or Ecm5 form an outlier group and are strongly correlated in S. pombe, but not in S. cerevisiae.
\end{abstract}

proteomic environments, as proteins found as stoichiometric subunits of more than one scaffold complex. Hyperlinks do not physically connect complexes; rather, they could exist for one of the following three reasons. First, hyperlinks might reflect a common ancestry for two complexes. In Chromatin Central, it is possible that Ino8oC and Swr1C are examples of complexes that share a common evolutionary origin because they not only share four subunits, but also share a similar function related to the histone variant H2A.z [43,59]. Second, hyperlinks may play a functional role to co-ordinate two complexes. If the hyperlink receives a signal via a post-translational modification, then two complexes should receive the signal at the same time and, hence, be co-regulated. Conversely, if a hyperlink recognizes an epitope or target, then both complexes will be coordinately recruited. In Chromatin Central, the Rpd3S/NuA4 hyperlink Eaf3 plays a role in coordinating these complexes [6o]. Third, the hyperlink may be a common tool recruited to the complex. In Chromatin Central, the Rvb1/Rvb2 heterodimeric helicase is a good example to consider. It is present in three complexes, Swr1C, Ino8oC and ASTRA, presumably because each requires a helicase for action in chromatin.

Altogether, we distinguished 21 proteomics hyperlinks in both Chromatin Central environments, 12 in S. cerevisiae and 9 in S. pombe (Figures 2 and 4; Table S6 in Additional data file 1). These proteins display a variety of physicochemical properties and domains (Table $\mathrm{S}_{5}$ in Additional data file 2 and Table S6 in Additional data file 1). For instance, in S. cerevisiae four hyperlink proteins are enzymes: Sc_Rvb1p and Sc_Rvb2p are DNA helicases, Sc_Rpd3p is a histone deacetylase, and Sc_Bdf1p is a protein kinase. Sc_Act1p and Sc_Arp4p are cytoskeleton and structural proteins. Sc_Tra1p belongs to a protein kinase family (although its catalytic activity has been questioned [61]), whereas no enzymatic activity has been reported for the other three proteins, Sc_Eaf3p, Sc_Yafop, Sc_Swc4p. Thus, the hyperlinks display diverse functional roles. However, they are all members of highly conserved protein families with clear homologues even in vertebrates. Also, half of the $S$. cerevisiae hyperlinks (6 out of 12) are essential, whereas only 3 essential genes were additionally found among the other 73 members of the environment.

Of the twelve hyperlinks in S. cerevisiae Chromatin Central, three are not conserved between the two yeasts. In two out of these three cases, the lost hyperlink is due to gene duplication or deletion. For Rpd3S and $\operatorname{Rpd}_{3} \mathrm{~L}$, Sin3 is a hyperlink in $S$. cerevisiae, but in S. pombe, both Clr6S and Clr6L have a dedicated Sin 3 homologue. In fact, S. pombe has three Sin3 paralogues, with Sp_Pst2p being exclusively found in Clr6S whereas the other two homologues, Sp_Pst1p and Sp_Pst3p, are exclusively found in Clr6L. For NuA4, SAGA/SLIK and ASTRA, Tra1 is a hyperlink in S. cerevisiae, but in S. pombe, the tra1 gene is duplicated with one paralogue present in ASTRA and another in NuA4 and, presumably, SAGA/SLIK. We have previously noted the same phenomenon regarding a lost hyperlink. In S. cerevisiae, Swd2 hyperlinks Set1C and $\mathrm{CPF}$; however, in S. pombe these two complexes each have a dedicated Swd2 paralogue, Swd2.1 and Swd 2.2. Notably, deletion of the gene encoding Swd2.1 did not provoke Swd2.2 to occupy the missing position in Sp_Set1C [7]. In the third case, Bdf1 is a hyperlink between NuA4 and Swr1C in S. cerevisiae, but in $S$. pombe, it is replaced by two non-orthologous proteins with a similar composition of domains (Tables 1 and 3 ; Table $\mathrm{S}_{5}$ in Additional data file 2).

Although we have documented only a few examples, this early concordance between hyperlinks and gene duplications/deletions is notable and indicates that a gene duplication in evolution may be especially advantageous when it is a proteomic hyperlink. Gene duplication permits the diversification of the encoded protein. However, unless all genes encoding interacting proteins, particularly members of the corresponding protein complex, are also duplicated, diversification of the duplicated protein will be constrained by the existing spectrum of protein-protein interactions [62]. If the duplicated gene encodes a hyperlink, then diversification of the duplicated protein will be less constrained because the duplications can associate and specialize with different complexes (Figure 6). Therefore, the gene duplication of a hyperlink may be more successful than other gene duplications. From a tech- 


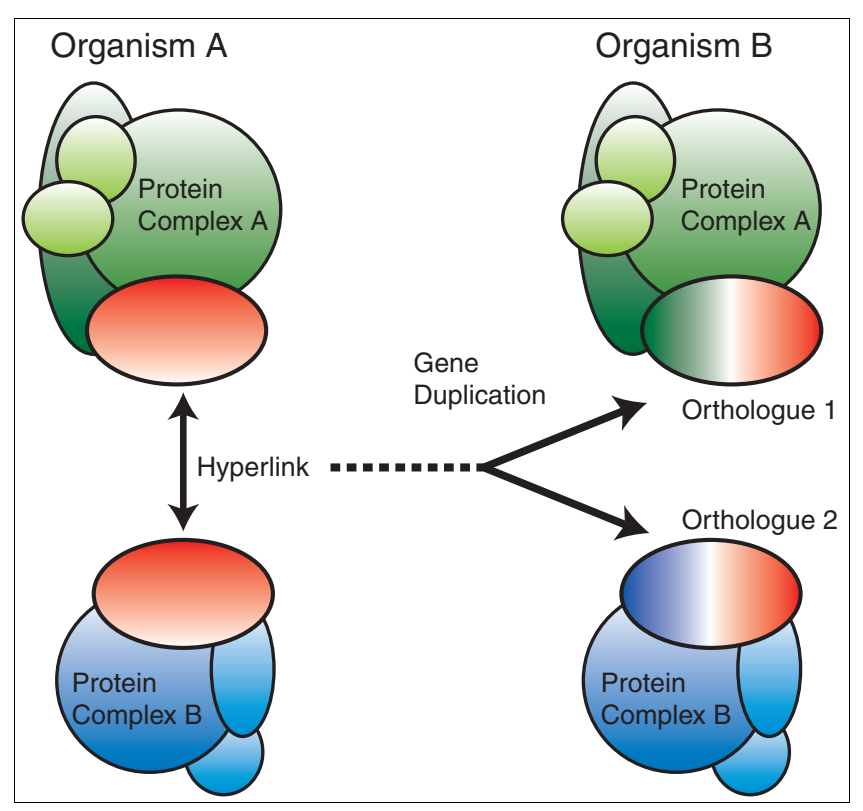

Figure 6

Several divergent proteomic hyperlinks between $S$. cerevisiae and S. pombe are due to gene duplications. Hence, hyperlinks provide a mechanism for the fixation of gene duplications.

nical point of view, we suggest that the tagging of hyperlinks as an entry point for mapping proteomic environments will be a rewarding focus for mapping and understanding proteomes.

\section{New complexes in Chromatin Central}

Despite the fact that this work was based on one of the most intensely studied proteomic environments to date, we documented four new subunits in the six known complexes (described above in Results). We also found three new complexes, including two more containing the histone deacetylase $\operatorname{Rpd}_{3}$, to add to the recently described $\mathrm{Rpd}_{3} \mathrm{~S}$ and $\mathrm{Rpd} 3 \mathrm{~L}$ complexes [24,25].

We found the three-member Sc_Snt2 complex in an Rpd3TAP pull down. Subsequently, we validated the complex by tagging Snt2 (Figure 7a). Sc_Snt2p and the other subunit, Sc_Ecm5p, contain several domains involved in chromatin regulation (Figure 7b). Sc_Snt2p (YGL131C) is one of 18 SANT domain-containing proteins in budding yeast and the sixth identified in Chromatin Central (Table $\mathrm{S}_{5}$ in Additional data file 2). Due to its JmjC domain, Sc_Ecm5p is a putative histone demethylase. Its PHD fingers have been reported to bind methylated $\mathrm{H}_{3} \mathrm{~K}_{3} 6$ [58].

We did not find a complex similar to Sc_Snt2C in S. pombe. Previously, we showed that the fission yeast orthologue of Sc_Snt2p is also found in a complex with the JmjC domain proteins Sp_Lid2p and Sp_Jmj3p [7,17]. However, these two complexes, Sc_Snt2C and Sp_Lid2C, are very different. From our IPs and Coomassie gels, we note that the Sc_Snt2C is much less abundant than either Rpd3S or Rpd3L.

The second new Rpd3-containing complex, Rpd3-LE, also contains a minor fraction of cellular Rpd3. Rpd3-LE is an extension of the Rpd3L complex, which includes the core of the Set3 complex. We have four reasons to be confident of this assignment. First, we reciprocally observed the relationship between Rpd3L and core Set3C in both yeasts. Second, in $S$. cerevisiae we observed only the core proteins of Set3C, but not the full eight-membered Set3C, associated with Rpd3L. This accords with our previous dissection of Sc_Set3C, which showed that the complex has a core of these four proteins [10]. Third, Sp_Set3C consists of only the four core proteins found in Sc_Set3C and does not include homologues of Sc_Hst1p or Sc_Hos4p. It also does not include a homologue of the cyclophilin Sc_Cph1p, which is required to fine-tune the sporulation-specific activity of Sc_Set3C [10,63]. Fourth, genetic interaction data clearly support the division of Sc_Set3C into core and extension components, as well as the interaction of the core with Rpd3L.

Taken together, these data indicate that Set3C has two versions, one that is small, common to both yeasts and interacts with $\operatorname{Rpd} 3 \mathrm{~L}$, and the another that is larger and specific to $S$. cerevisiae. Sc_Set3C functions during vegetative growth to regulate several inducible genes and to co-operate with Rpd3 [33-35]. It has also been shown to be a negative regulator during meiosis [10]. Partly because transcriptional control of meiosis appears to be poorly conserved [64], we suggest that the vegetative functions in $S$. cerevisiae entirely relate to the smaller complex.

We also discovered the ASTRA complex, which is composed of orthologous subunits in both yeasts and contains a Tra1 member of the ATM-like kinase family (Figures 2, 4 and 7C,D; Table 4). ASTRA includes the ATP-dependent DNA helicase Rvb1/2 heterodimer, the telomere binding protein Tel2p together with two uncharacterized Tel2-interacting proteins (Tti1p and Tti2p), and a WD-repeat containing protein (Asa1p) of unknown function in both yeasts.

Protein assemblies similar to ASTRA have not been identified in other organisms. However, five subunits have clear human homologues so the complex may be widespread. Furthermore, Sc_Tel2p, as well as the C. elegans (CLK-2 [65]) and human (TELO [66]) orthologues are required for telomere length regulation. Sc_Tel2p also influences telomere position effect and interacts directly with double-stranded telomeric DNA [67,68]. Recently, Hayashi et al. [69] suggested that a Tel2-Tti1 heterodimer recognizes a common domain of phosphatidyl inositol 3-kinase related kinases (PIKK) in the fission yeast and is a component of multiple PIKK assemblies, which corroborates our findings in $S$. cerevisiae (Table $\mathrm{S} 2$ in Additional data file 1). Hence, we suggest that ASTRA is the Tra-specific Tel2/CLK-2/TELO complex involved in telom- 
(a)

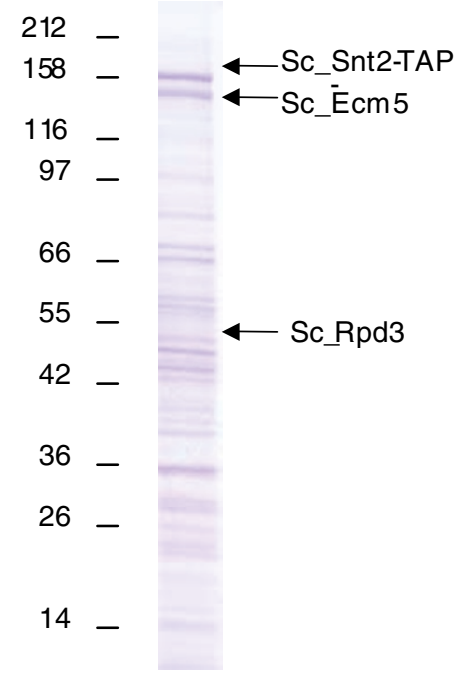

(c)

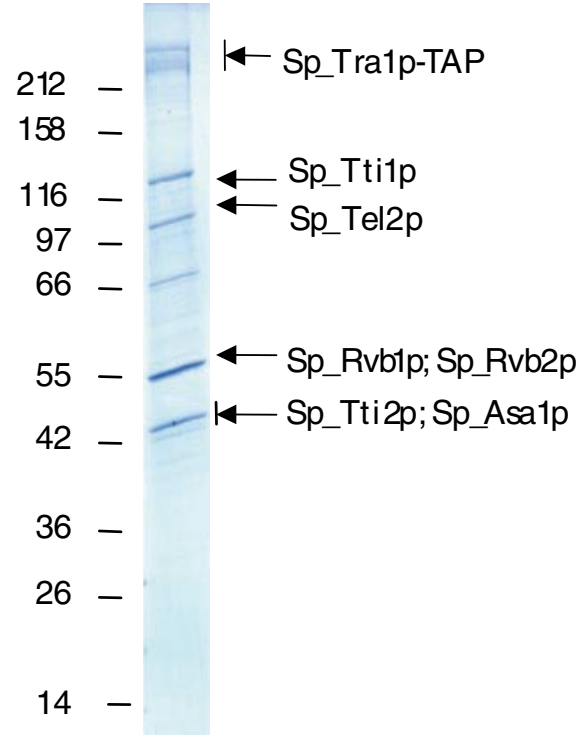

(b)

ScSnt2 / YGL131C

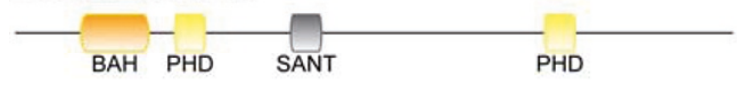

ScEcm5 / YMR176w

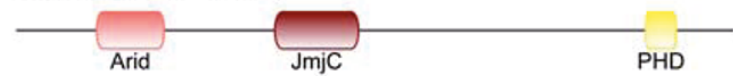

ScRpd3 / YNL330c

Hist_deacetyl

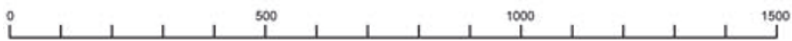

(d)

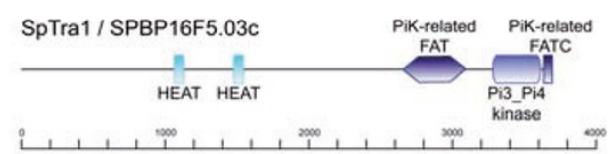

SpTti1 / SPCC622.13c

ARM repeat

SpTel2 / SPAC458.03

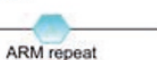

SpRvb1 / SPAC458.03

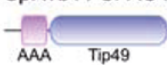

SpRvb2 / SPBC83.08

$$
\text { Tip49 }
$$

SpTti2 / SPBC1604.17c

SpAsa1 / SPAC1006.02

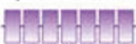

WD40

Figure 7 (see legend on following page) 
Figure 7 (continued)

New protein complexes in Chromatin Central. (a) Immuno-isolation of the Sc_Snt2C complex and (b) domain structure of its subunits. (c) Immunoisolation of the Sp_ASTRA complex and (d) domain structure of its subunits. In (a, c), only the relevant protein bands are annotated. The full list of identified proteins is provided in Table SI in Additional data file I.

eric chromatin regulation and will be found in many eukaryotes.

The stringency of our protein selection criteria may have excluded some lowly abundant interactors, as well as proteins only interacting with a particular subunit of the complex, rather than with the entire complex cores. This might include several interesting possible further connections to Chromatin Central (Tables S2, S3 and $\mathrm{S}_{4}$ in Additional data file 1). For example, we observed several subunits of the SWI-SNF global transcription activator complex [70-72], RSC chromatin remodeling complex [72,73], Regulator of Nucleolar silencing and Telophase exit (RENT) [74,75], Anaphase Promoting Complex (APC) [37], cytoplasm to nucleus signaling complexes TORC1 and TORC2 $[69,76]$, the proteasome, DNA replication licensing complex [77], the CCR4/NOT transcription complex [78] and various transcription factors.

The histone deacetylases Rpd3p and Clr6p pulled down the complete TRiC chaperonin complex [79] in S. cerevisiae and $S$. pombe, respectively (Figures 2 and 4; Tables $\mathrm{S}_{3}$ and $\mathrm{S}_{4}$ in Additional data file 1). Similarly, TRiC was co-purified with the Hos2 deacetylase complex Set3C in S. cerevisiae [5]. Hence, we suggest that TriC chaperonin activity is specifically related to type I histone deacetylases.

\section{Conclusion}

Comparative proteomics remains undeveloped because the generation of reliable proteomic data remains challenging. A variety of candidate approaches using synthetic expression libraries, bioinformatics, or high throughput methodologies have been applied to tackle the challenge. The best datasets have been acquired by affinity purification approaches based on authentic expression levels. Strategies to apply this conclusion at a genome scale have been developed for yeast $[11,12]$ and are being developed for mammalian systems [8o]. Based on the conclusions drawn here, we suggest that comparative proteomics will become a valuable complement for proteomic mapping because it presents alternative ways to validate data. Proteins interacting with Set3 illustrate this point well. In $S$. cerevisiae, the interaction between $\mathrm{Rpd}_{3} \mathrm{~L}$ and the core of Set3C is sub-stoichiometric and obscured by the existence of alternative Rpd3 and Set3 complexes. However, our reciprocal identification of the Rps3-LE complex in both yeasts secures the observation, which was also supported by genetic interaction studies in both yeasts. Comparative proteomics can also guide the investigation of new proteomes. In particular, projecting yeast data onto mamma- lian proteomes has relevance for medicine. Although the available datasets are incomplete, protein assemblies that are, apparently, orthologous to the yeast complexes $\mathrm{NuA}_{4}$, Swr1C, INO8oC and Set3C, along with Rpd3 interactors, have been partially characterized (Figures $\mathrm{S}_{5}$ and $\mathrm{S}_{7}$ in Additional data file 2) [81-92] and suggest a highly conserved proteomic environment. Potentially, the orthologous complexes in humans are hyperlinked into a similar scaffold architecture, although different protein orthologues are recruited as hyperlinks. Because of multiple gene duplications, human assemblies are more complicated (such as hHDACs). However, comparative proteomics can guide the search for missing human subunits or even protein complexes, like the ASTRA orthologue.

Our intense focus on a section of the $S$. cerevisiae proteome also revealed new details. These further gains in proteomic accuracy are partly due to recent performance improvements delivered by LC-MS/MS. The improved capacity for protein identification above background and noise in complex mixtures permits a greater ability to distinguish sub-stoichiometric interactors from background. This greater depth has implications for biochemical practice in two ways. First, the reliance on candidate approaches to map the proteome, such as two-hybrid or bioinformatics, has been lessened because affinity chromatography and mass spectrometry can be used to deliver reliable sub-stoichiometric data, in addition to the well established capacity to document stoichiometric interactions. Second, classic biochemistry, which includes tagging approaches like the TAP method, delivered highly purified fractions based on multiple purification steps. However, weak interactions were inevitably lost during multiple steps of purification. Now, a new logic is emerging based on minimizing the biochemical procedure so that more weak and sub-stoichiometric interactions are preserved. Although these less purified preparations will have increased background, mass spectrometry can now identify large numbers of proteins in complex mixtures. Its combination with protein quantification and bioinformatics should largely eliminate background proteins, thus opening new paths to map proteomes accurately at greater depth. Given greater accuracy, comparative proteomics will become a leading source of insight into eukaryotic cellular and developmental mechanics. 


\section{Materials and methods Epitope tagging of genes and isolation of protein complexes}

Transformations for both yeasts were performed as described $[7,9]$. Genes of interest were tagged by in-frame fusion of the ORFs with a PCR generated targeting cassette encoding the TAP-tag and a selectable marker. Correct cassette integrations were confirmed by PCR and Western blot analysis. Two $S$. cerevisiae strains with TAP-tagged genes YGRo99W and YJR136C were obtained from Euroscarf (Frankfurt am Main, Germany). Breaking and extraction of yeast cells was performed as described [7] with modifications [10]. Purified proteins were concentrated according to Wessel and Fluegge [93] and loaded onto one-dimensional gradient (6-18\%) polyacrylamide gels.

\section{Protein separation and in-gel digestion}

Protein bands were visualized by staining with Coomassie. Full lanes were cut into approximately 30-40 slices; to enhance the detection dynamic range, visible bands were always sliced separately. Excised gel plugs were cut into approximately $1 \mathrm{~mm} \times 1 \mathrm{~mm} \times 1 \mathrm{~mm}$ cubes and in-gel digested with sequencing grade modified porcine trypsin (catalogue number V5111, Promega, Mannheim, Germany) as described in [94]. Then, $1 \mu \mathrm{l}$ aliquots were withdrawn directly from in-gel digests for the protein identification by MALDI peptide mapping. The rest of the peptide material was extracted from the gel pieces with $5 \%$ formic acid and acetonitrile and recovered peptides dried down in a vacuum centrifuge.

\section{Protein identification by MALDI peptide mass mapping} Where specified, $1 \mu \mathrm{l}$ aliquots of in-gel digests were analyzed on a REFLEX IV mass spectrometer (Bruker Daltonics, Bremen, Germany) using AnchorChip probes (Bruker Daltonics) as described in [95,96]. Peaks were manually selected and their $m / z$ searched against MSDB protein database of $S$. cerevisiae or $S$. pombe species using MASCOT 2.0 software (Matrix Science Ltd, London, UK), installed on a local two CPU server. Mass tolerance was set to 50 ppm; variable modifications: oxidized methionines; one misscleavage per tryptic peptide sequence was allowed. Spectra were calibrated externally using $\mathrm{m} / \mathrm{z}$ of known abundant trypsin autolysis products as references. Protein hits whose MOWSE score exceed the value of 51 (the threshold confidence score suggested by MASCOT for $p<0.05$ and the corresponding species-specific database) were considered significant, but were only accepted upon further manual inspection, which made sure that the $m$ / $z$ of all major peaks in the spectrum matched the masses of peptides from the corresponding protein sequences or known tryptic autolysis products.

\section{Protein identification by LC-MS/MS}

Dried peptide extracts were re-dissolved in $20 \mu \mathrm{l}$ of $0.05 \%$ (v/ v) trifluoroacetic acid and $4 \mu \mathrm{l}$ were injected using a FAMOS autosampler into a nanoLC-MS/MS Ultimate system
(Dionex, Amstersdam, The Netherlands) interfaced on-line to a linear ion trap LTQ mass spectrometer (Thermo Fisher Scientific, San Jose, CA, USA). The mobile phase was 95:5 $\mathrm{H}_{2} \mathrm{O}$ :acetonitrile (v/v) with $0.1 \%$ formic acid (solvent $\mathrm{A}$ ) and 20:80 $\mathrm{H}_{2} \mathrm{O}$ :acetonitrile (v/v) with $0.1 \%$ formic acid (solvent $\mathrm{B}$, Lichrosolv grade). Peptides were first loaded onto a trapping microcolumn C18 PepMAP10o ( $1 \mathrm{~mm} \times 300 \mathrm{~mm}$ ID, 5 $\mathrm{mm}$, Dionex) in $0.05 \%$ trifluoroacetic acid at a flow rate of 20 $\mathrm{ml} /$ minute. After 4 minutes they were back-flush eluted and separated on a nanocolumn C18 PepMAP10o $(15 \mathrm{~cm} \times 75 \mu \mathrm{m}$ ID, $3 \mu \mathrm{m}$, Dionex, Sunnyville, CA, USA) at a flow rate of 200 $\mathrm{nl} /$ minute in the mobile phase gradient: from $5-20 \%$ of solvent $\mathrm{B}$ in 20 minutes, $20-50 \% \mathrm{~B}$ in 16 minutes, $50-100 \% \mathrm{~B}$ in 5 minutes, $100 \% \mathrm{~B}$ during 10 minutes, and back to $5 \% \mathrm{~B}$ in 5 minutes; \%B refers to the solvent $B$ content $(v / v)$ in $A+B$ mixture. Peptides were infused into the mass spectrometer via a dynamic nanospray probe (Thermo Fisher Scientific) and analyzed in positive mode. Uncoated needles Silicatip, $20 \mu \mathrm{m}$ ID, $10 \mu \mathrm{m}$ tip (New Objective, Woburn, MA, USA) were used with a spray voltage of $1.8 \mathrm{kV}$, and the capillary transfer temperature was set to $200^{\circ} \mathrm{C}$. In a typical data-dependent acquisition cycle controlled by Xcalibur 1.4 software (Thermo Fisher Scientific), the four most abundant precursor ions detected in the full MS survey scan ( $\mathrm{m} / \mathrm{z}$ range of 350-1,500) were isolated within a $4.0 \mathrm{amu}$ window and fragmented. MS/ MS fragmentation was triggered by a minimum signal intensity threshold of 500 counts and carried out at the normalized collision energy of $35 \%$. Spectra were acquired under automatic gain control in one microscan for survey spectra and in three microscans for MS/MS spectra with a maximal ion injection time of $100 \mathrm{~ms}$ per each microscan. $M / z$ of the fragmented precursors were then dynamically excluded for another $60 \mathrm{~s}$. No precompiled exclusion lists were applied.

MS/MS spectra were exported as dta (text format) files using BioWorks 3.1 software (Thermo Fisher Scientific) under the following settings: peptide mass range, 500-3,500 Da; minimal total ion intensity threshold, 1,00o; minimal number of fragment ions, 15; precursor mass tolerance, $1.4 \mathrm{amu}$; group scan, 1 ; minimum group count, 1.

\section{Processing of MS/MS spectra and database searches}

Dta files were merged into a single MASCOT generic format (mgf) file and searched against a database of $S$. cerevisiae or $S$. pombe proteins using MASCOT v.2.2 installed on a local two CPU server. Tolerance for precursor and fragment masses was 2.0 and 0.5 Da, respectively; instrument profile, ESI-Trap; variable modification, oxidation (methionine); allowed number of miscleavages, 1 ; peptide ion score cut-off, 15 .

Hits were considered confident if two or more MS/MS spectra matched the database sequences and their peptide ion scores exceeded the value of 31 (the threshold score suggested by MASCOT for confident matching of a single peptide sequence at $p<0.05)$. For each identified protein, the number of 
matched peptides and of MS/MS spectra were exported from MASCOT output to Excel spreadsheets using a script developed in-house, which further created a non-redundant list of protein hits detected in all analyzed bands of the same IP experiment. If the same protein was sequenced in several bands, only the analysis that produced the highest number of matched peptides and spectra was reported.

\section{Protein identification in the S. pombe genome database} Where specified, recovered tryptic peptides were sequenced de novo by nanoelectrospray tandem mass spectrometry on a QSTAR Pulsar $i$ quadrupole time-of-flight mass spectrometer (MDS Sciex, Concord, Canada) as described [97]. MS/MS spectra were interpreted manually using BioAnalyst QS v.1.1 software and candidate sequences searched against the genomic sequence of $S$. pombe by the tblastn program at the NCBI BLAST server. The search found, with several matched peptides, a non-annotated segment at chromosome 1. Subsequently, the full length sequence of the gene was produced by 5 -RACE and determined at the DNA sequencing facility in MPI CBG, Dresden.

\section{Bioinformatic identification of orthologous genes}

Protein sequence database searches were carried out using a stand-alone version of NCBI-BLAST and the PSI-BLAST (position-specific iterated BLAST) interface at the NCBI [98]. To identify orthologous genes in $S$. cerevisiae and $S$. pombe, we performed automated BLAST searches using sequences of all subunits of all identified complexes. Potential orthologues were further evaluated by reciprocal BLAST searches using all hits whose $E$-values were less than 10-fold higher than the $E$ value of the best hit. Best hits in reciprocal searches were regarded as orthologues. If no reciprocal best hit pair was identified, PSI-BLAST searches were carried out against all fungal sequences in the non-redundant protein database. $E$ values and PSI-BLAST iterations for highly divergent orthologues are shown in Figure $\mathrm{S}_{3}$ in Additional data file 2. Multiple sequence alignments also shown in Figure $\mathrm{S}_{3}$ in Additional data file 2 were done manually by using pair-wise alignments produced by BLAST as a template. Residues that were conserved in at least $75 \%$ of sequences are highlighted. Identification of protein sequence domains was carried out using a stand-alone version of the InterproScan software [99] against the Superfamily and HMM-Pfam databases using default settings.

\section{Genetic interactions}

Quantitative genetic interaction profiles in $S$. cerevisiae and $S$. pombe were generated as described $[51,100]$. Pearson correlation coefficients were calculated between all possible pairs of genetic profiles for an overlapping set of genes in both species and the data corresponding to Set3 and Hos2 (Hda1) are presented as scatter plots in Figure 5 .

\section{Abbreviations}

A-index: Abundance index; IP: immunoaffinity purification; LC-MS/MS: liquid chromatography tandem mass spectrometry; MALDI MS: matrix-assisted laser desorption/ionization mass spectrometry; ORF: open reading frame; TAP: tandem affinity purification.

\section{Authors' contributions}

$\mathrm{AR}, \mathrm{DS}, \mathrm{LB}$ and CS performed gene tagging and IP experiments. Anna S and HT analyzed the isolated proteins by mass spectrometry. Anna S processed the identification data and determined Chromatin Central architecture in both yeasts. $\mathrm{BH}$ identified pairs of orthologous genes and determined functional domains in Chromatin Central proteins. AR and NK performed the genetic interaction experiments. Andrej S and AFS conceived the study, and together with other coauthors interpreted the results and wrote the manuscript. All authors have read and approved the manuscript.

\section{Additional data files}

Additional data file 1 contains five worksheets. Table S1 lists common background proteins observed in TAP experiments in $S$. cerevisiae and $S$. pombe. Table S2 presents full lists of proteins identified in all immunoprecipitation experiments in both yeasts. Tables $\mathrm{S}_{3}$ and $\mathrm{S}_{4}$ are master tables of identified proteins used for compiling Chromatin Central in $S$. cerevisiae and $S$. pombe, respectively. Table S6 lists physical properties and bioinformatic annotations of proteomics hyperlinks. Additional data file 2 contains five figures and two tables in pdf format. Figure S1 plots A-indices of six protein standards versus corresponding protein loadings. Figure S2 presents gel images of immunoprecipitation experiments used for compiling Chromatin Central in $S$. cerevisiae. Figure S3 presents multiple sequence alignments for several members of Chromatin Central in S. cerevisiae, whose similarity to corresponding $S$. pombe proteins was marginal. Figure $\mathrm{S}_{4}$ presents mass spectrometric identification of the novel 17 $\mathrm{kDa}$ protein in $S$. pombe, its full-length amino acid sequence and its alignment with the corresponding region of the genome. Figure S5 presents a plausible molecular architecture of the human Chromatin Central (partly supported by already published evidence). Table $\mathrm{S}_{5}$ lists domain composition of orthologous complexes within Chromatin Central in both yeasts. Table S7 lists plausible members of human Chromatin Central, considering their homology to corresponding proteins in both yeast proteomic environments and published evidences.

\section{Acknowledgements}

We are grateful for members of the Shevchenko and Stewart groups for continuous support and stimulating discussions. Work in the Shevchenko lab was, in part, supported by the grant IROIGM070986-0IAI from NIH NIGMS. Work in the Stewart lab was supported by funding from the BMBF (Bundesministerium für Bildung und Forschung), Proteomics Program, and 
the 6th Framework Program of the European Union, Integrated project EuTRACC (LSHG-CT-2007-037445).

\section{References}

I. von Mering C, Krause R, Snel B, Cornell M, Oliver SG, Fields S, Bork $P$ : Comparative assessment of large-scale data sets of protein-protein interactions. Nature 2002, 4I7:399-403.

2. Gavin AC, Bosche M, Krause R, Grandi P, Marzioch M, Bauer A, Schultz J, Rick JM, Michon AM, Cruciat CM, Remor M, Hofert C, Schelder M, Brajenovic M, Ruffner H, Merino A, Klein K, Hudak M, Dickson D, Rudi T, Gnau V, Bauch A, Bastuck S, Huhse B, Leutwein C, Heurtier MA, Copley RR, Edelmann A, Querfurth E, Rybin V, et al.: Functional organization of the yeast proteome by systematic analysis of protein complexes. Nature 2002, 4I5:I4I-I 47.

3. Titz B, Schlesner M, Uetz P: What do we learn from highthroughput protein interaction data? Expert Rev Proteomics 2004, I:III-I2I.

4. Goll J, Uetz P: The elusive yeast interactome. Genome Biol 2006, 7:223.

5. Shevchenko A, Schaft D, Roguev A, Pijnappel WWMP, Stewart AF, Shevchenko A: Deciphering protein complexes and protein interaction networks by tandem affinity purification and mass spectrometry: analytical perspective. $\mathrm{Mol}$ Cell Proteomics 2002, I:204-2I2

6. Deshaies RJ, Seol JH, McDonald WH, Cope G, Lyapina S, Shevchenko A, Shevchenko A, Verma R, Yates JR III: Charting the protein complexome in yeast by mass spectrometry. Mol Cell Proteomics 2002, 1:3-10.

7. Roguev A, Shevchenko A, Schaft D, Thomas H, Stewart AF: A comparative analysis of an orthologous proteomic environment in the yeasts Saccharomyces cerevisiae and Schizosaccharomyces pombe. Mol Cell Proteomics 2004, 3: I25-I32.

8. Hirsh E, Sharan R: Identification of conserved protein complexes based on a model of protein network evolution. Bioinformatics 2007, 23: el 70-I76.

9. Rigaut G, Shevchenko A, Rutz B, Wilm M, Mann M, Seraphin B: A generic protein purification method for protein complex characterization and proteome exploration. Nat Biotechnol 1999, 17:1030-1032.

10. Pijnappel WW, Schaft D, Roguev A, Shevchenko A, Tekotte H, Wilm M, Rigaut G, Seraphin B, Aasland R, Stewart AF: The S. cerevisiae SET3 complex includes two histone deacetylases, Hos 2 and Hst I, and is a meiotic-specific repressor of the sporulation gene program. Genes Dev 200I, 15:299I-3004.

11. Gavin AC, Aloy P, Grandi P, Krause R, Boesche M, Marzioch M, Rau C, Jensen LJ, Bastuck S, Dumpelfeld B, Edelmann A, Heurtier MA, Hoffman V, Hoefert C, Klein K, Hudak M, Michon AM, Schelder M, Schirle M, Remor M, Rudi T, Hooper S, Bauer A, Bouwmeester T, Casari G, Drewes G, Neubauer G, Rick JM, Kuster B, Bork P, et al.: Proteome survey reveals modularity of the yeast cell machinery. Nature 2006, 440:63I-636.

12. Krogan NJ, Cagney G, Yu H, Zhong G, Guo X, Ignatchenko A, Li J, Pu $S$, Datta N, Tikuisis AP, Punna T, Peregrin-Alvarez JM, Shales $M$, Zhang X, Davey M, Robinson MD, Paccanaro A, Bray JE, Sheung A, Beattie B, Richards DP, Canadien V, Lalev A, Mena F, Wong P, Starostine A, Canete MM, Vlasblom J, Wu S, Orsi C, et al.: Global landscape of protein complexes in the yeast Saccharomyces cerevisiae. Nature 2006, 440:637-643.

13. Collins SR, Kemmeren P, Zhao XC, Greenblatt JF, Spencer F, Holstege FC, Weissman JS, Krogan NJ: Toward a comprehensive atlas of the physical interactome of Saccharomyces cerevisiae. Mol Cell Proteomics 2007, 6:439-450.

14. Kouzarides T: Chromatin modifications and their function. Cell 2007, I 28:693-705.

15. Shevchenko A, Zachariae W, Shevchenko A: A strategy for the characterization of protein interaction networks by mass spectrometry. Biochem Soc Trans 1999, 27:549-554.

16. Seol JH, Shevchenko A, Shevchenko A, Deshaies RJ: Skp I forms multiple protein complexes, including RAVE, a regulator of V-ATPase assembly. Nat Cell Biol 200I, 3:384-391.

17. Roguev A, Schaft D, Shevchenko A, Aasland R, Stewart AF: High conservation of the Set I/Rad6 axis of histone 3 lysine 4 methylation in budding and fission yeasts. I Biol Chem 2003, 278:8487-8493.

18. Graumann J, Dunipace LA, Seol JH, McDonald WH, Yates JR 3rd,
Wold BJ, Deshaies RJ: Applicability of tandem affinity purification MudPIT to pathway proteomics in yeast. Mol Cell Proteomics 2004, 3:226-237.

19. Link AJ, Fleischer TC, Weaver CM, Gerbasi VR, Jennings JL: Purifying protein complexes for mass spectrometry: applications to protein translation. Methods 2005, 35:274-290.

20. Ghaemmaghami S, Huh WK, Bower K, Howson RW, Belle A, Dephoure N, O'Shea EK, Weissman JS: Global analysis of protein expression in yeast. Nature 2003, 425:737-74I.

21. Wohlschlegel JA, Yates JR: Proteomics: where's Waldo in yeast? Nature 2003, 425:67I-672.

22. Huh WK, Falvo JV, Gerke LC, Carroll AS, Howson RW, Weissman JS, O'Shea EK: Global analysis of protein localization in budding yeast. Nature 2003, 425:686-69l.

23. Kumar A, Agarwal S, Heyman JA, Matson S, Heidtman M, Piccirillo S Umansky L, Drawid A, Jansen R, Liu Y, Cheung KH, Miller P, Gerstein M, Roeder GS, Snyder M: Subcellular localization of the yeast proteome. Genes Dev 2002, 16:707-719.

24. Carrozza MJ, Li B, Florens L, Suganuma T, Swanson SK, Lee KK, Shia W], Anderson S, Yates J, Washburn MP, Workman JL: Histone H3 methylation by Set 2 directs deacetylation of coding regions by $R p d 3 S$ to suppress spurious intragenic transcription. Cell 2005, 1 23:581-592.

25. Keogh MC, Kurdistani SK, Morris SA, Ahn SH, Podolny V, Collins SR, Schuldiner M, Chin K, Punna T, Thompson NJ, Boone C, Emili A, Weissman JS, Hughes TR, Strahl BD, Grunstein M, Greenblatt JF, Buratowski S, Krogan NJ: Cotranscriptional set 2 methylation of histone $\mathbf{H} 3$ lysine 36 recruits a repressive Rpd3 complex. Cell 2005, I 23:593-605.

26. Allard S, Utley RT, Savard J, Clarke A, Grant P, Brandl CJ, Pillus L, Workman JL, Cote J: NuA4, an essential transcription adaptor/ histone $\mathrm{H} 4$ acetyltransferase complex containing Esa Ip and the ATM-related cofactor Tra Ip. EMBO J 1999, I 8:5 I08-5II9.

27. Brown CE, Howe L, Sousa K, Alley SC, Carrozza MJ, Tan S, Workman JL: Recruitment of HAT complexes by direct activator interactions with the ATM-related Tral subunit. Science 200I, 292:2333-2337.

28. Shen X, Mizuguchi G, Hamiche A, Wu C: A chromatin remodelling complex involved in transcription and DNA processing. Nature 2000, 406:54I-544.

29. Krogan NJ, Keogh MC, Datta N, Sawa C, Ryan OW, Ding H, Haw RA, Pootoolal J, Tong A, Canadien V, Richards DP, Wu X, Emili A, Hughes TR, Buratowski S, Greenblatt JF: A Snf2 family ATPase complex required for recruitment of the histone H2A variant Htzl. Mol Cell 2003, I2:1565-1576.

30. Aasland R, Stewart AF, Gibson T: The SANT domain: a putative DNA-binding domain in the SWI-SNF and ADA complexes, the transcriptional co-repressor N-CoR and TFIIIB. Trends Biochem Sci 1996, 21:87-88.

31. Singer MS, Kahana A, Wolf AJ, Meisinger LL, Peterson SE, Goggin C, Mahowald M, Gottschling DE: Identification of high-copy disruptors of telomeric silencing in Saccharomyces cerevisiae. Genetics 1998, 150:613-632.

32. Krogan NJ, Baetz K, Keogh MC, Datta N, Sawa C, Kwok TC, Thompson NJ, Davey MG, Pootoolal J, Hughes TR, Emili A, Buratowski S, Hieter P, Greenblatt JF: Regulation of chromosome stability by the histone H2A variant $\mathrm{Htzl}$, the Swr I chromatin remodeling complex, and the histone acetyltransferase NuA4. Proc Natl Acad Sci USA 2004, 1 0 I: | 3513-135 I8.

33. Burgess SM, Ajimura M, Kleckner N: GCN5-dependent histone $\mathrm{H} 3$ acetylation and RPD3-dependent histone $\mathrm{H} 4$ deacetylation have distinct, opposing effects on IME2 transcription, during meiosis and during vegetative growth, in budding yeast. Proc Natl Acad Sci USA 1999, 96:6835-6840.

34. Wang A, Kurdistani SK, Grunstein M: Requirement of Hos2 histone deacetylase for gene activity in yeast. Science 2002, 298: $14|2-14| 4$.

35. Sharma VM, Tomar RS, Dempsey AE, Reese JC: Histone deacetylases RPD 3 and HOS2 regulate the transcriptional activation of DNA damage-inducible genes. Mol Cell Biol 2007, 27:3199-3210.

36. Tong $A H$, Lesage G, Bader GD, Ding $H, X u H, X i n X$, Young J, Berriz GF, Brost RL, Chang M, Chen Y, Cheng X, Chua G, Friesen H, Goldberg DS, Haynes J, Humphries C, He G, Hussein S, Ke L, Krogan N, Li Z, Levinson JN, Lu H, Menard P, Munyana C, Parsons AB, Ryan O, Tonikian R, Roberts T, et al.: Global mapping of the yeast genetic interaction network. Science 2004, 303:808-8I3.

37. Yoon HJ, Feoktistova A, Wolfe BA, Jennings JL, Link AJ, Gould KL: 
Proteomics analysis identifies new components of the fission and budding yeast anaphase-promoting complexes. Curr Biol 2002, I 2:2048-2054.

38. Nicolas E, Yamada T, Cam HP, Fitzgerald PC, Kobayashi R, Grewal SI: Distinct roles of HDAC complexes in promoter silencing, antisense suppression and DNA damage protection. Nat Struct Mol Biol 2007, 14:372-380.

39. Minoda A, Saitoh S, Takahashi K, Toda T: BAF53/Arp4 homolog Alp5 in fission yeast is required for histone $\mathrm{H} 4$ acetylation, kinetochore-spindle attachment, and gene silencing at centromere. Mol Biol Cell 2005, 16:316-327.

40. Pandey R, Muller A, Napoli CA, Selinger DA, Pikaard CS, Richards EJ, Bender J, Mount DW, Jorgensen RA: Analysis of histone acetyltransferase and histone deacetylase families of Arabidopsis thaliana suggests functional diversification of chromatin modification among multicellular eukaryotes. Nucleic Acids Res 2002, 30:5036-5055.

41. Gomez EB, Espinosa JM, Forsburg SL: Schizosaccharomyces pombe mst2+ encodes a MYST family histone acetyltransferase that negatively regulates telomere silencing. Mol Cell Biol 2005, 25:8887-8903

42. Mizuguchi G, Shen X, Landry J, Wu WH, Sen S, Wu C: ATP-driven exchange of histone H2AZ variant catalyzed by SWR I chromatin remodeling complex. Science 2004, 303:343-348.

43. Bao $Y$, Shen $X$ : INO80 subfamily of chromatin remodeling complexes. Mutat Res 2007, 6I 8:18-29.

44. Ahmed S, Palermo C, Wan S, Walworth NC: A novel protein with similarities to $\mathbf{R b}$ binding protein $\mathbf{2}$ compensates for loss of Chkl function and affects histone modification in fission yeast. Mol Cell Biol 2004, 24:3660-3669.

45. Aasland R, Gibson TJ, Stewart AF: The PHD finger: implications for chromatin-mediated transcriptional regulation. Trends Biochem Sci 1995, 20:56-59.

46. Lu PJ, Sundquist K, Baeckstrom D, Poulsom R, Hanby A, Meier-Ewert $\mathrm{S}$, Jones T, Mitchell M, Pitha-Rowe P, Freemont P, Taylor-Papadimitriou J: A novel gene (PLU-I) containing highly conserved putative DNA/chromatin binding motifs is specifically upregulated in breast cancer. J Biol Chem 1999, 274:15633-15645.

47. Clissold PM, Ponting CP: JmjC: cupin metalloenzyme-like domains in jumonji, hairless and phospholipase A2beta. Trends Biochem Sci 200I, 26:7-9.

48. Dul BE, Walworth NC: The plant homeodomain fingers of fission yeast Mscl exhibit E3 ubiquitin ligase activity. J Biol Chem 2007, 282: I8397-18406.

49. Klose RJ, Kallin EM, Zhang Y: JmjC-domain-containing proteins and histone demethylation. Nat Rev Genet 2006, 7:715-727.

50. Mitsuzawa $H$, Ishihama $A$ : Identification of histone H4-like TAF in Schizosaccharomyces pombe as a protein that interacts with WD repeat-containing TAF. Nucleic Acids Res 2002, 30:1952-1958.

51. Collins SR, Miller KM, Maas NL, Roguev A, Fillingham J, Chu CS, Schuldiner M, Gebbia M, Recht J, Shales M, Ding H, Xu H, Han J, Ingvarsdottir K, Cheng B, Andrews B, Boone C, Berger SL, Hieter P, Zhang Z, Brown GW, Ingles CJ, Emili A, Allis CD, Toczyski DP, Weissman JS, Greenblatt JF, Krogan NJ: Functional dissection of protein complexes involved in yeast chromosome biology using a genetic interaction map. Nature 2007, 446:806-8I0.

52. Roguev A, Bandyopadhyay S, Zofall M, Zhang K, Fischer T, Collins SR, Qu H, Shales M, Park HO, Hayles J, Hoe KL, Kim DU, Ideker T, Grewal Sl, Weissman JS, Krogan NJ: Conservation and rewiring of functional modules revealed by an epistasis map in fission yeast. Science 2008, 322:405-4I0.

53. Roguev A, Wiren M, Weissman JS, Krogan NJ: High-throughput genetic interaction mapping in the fission yeast Schizosaccharomyces pombe. Nat Methods 2007, 4:86I-866.

54. Hudson BP, Martinez-Yamout MA, Dyson HJ, Wright PE: Solution structure and acetyl-lysine binding activity of the GCN5 bromodomain. J Mol Biol 2000, 304:355-370.

55. Nielsen PR, Nietlispach D, Mott HR, Callaghan J, Bannister A, Kouzarides T, Murzin AG, Murzina NV, Laue ED: Structure of the HPI chromodomain bound to histone $\mathrm{H} 3$ methylated at lysine 9. Nature 2002, 416:103-107.

56. Pena PV, Davrazou F, Shi X, Walter KL, Verkhusha VV, Gozani O, Zhao R, Kutateladze TG: Molecular mechanism of histone H3K4me3 recognition by plant homeodomain of ING2. Nature 2006, 442:100-103.

57. Wysocka J, Swigut T, Xiao H, Milne TA, Kwon SY, Landry J, Kauer M, Tackett AJ, Chait BT, Badenhorst P, Wu C, Allis CD: A PHD finger of NURF couples histone $\mathrm{H} 3$ lysine 4 trimethylation with chromatin remodelling. Nature 2006, 442:86-90.

58. Shi X, Kachirskaia I, Walter KL, Kuo JH, Lake A, Davrazou F, Chan SM, Martin DG, Fingerman IM, Briggs SD, Howe L, Utz PJ, Kutateladze TG, Lugovskoy AA, Bedford MT, Gozani O: Proteome-wide analysis in Saccharomyces cerevisiae identifies several PHD fingers as novel direct and selective binding modules of histone $\mathbf{H 3}$ methylated at either lysine $\mathbf{4}$ or lysine 36. J Biol Chem 2007, 282:2450-2455.

59. van Attikum H, Fritsch O, Gasser SM: Distinct roles for SWR I and INO80 chromatin remodeling complexes at chromosomal double-strand breaks. $E M B O$ | 2007, 26:4| | 3-4 | 25 .

60. Joshi AA, Struhl K: Eaf3 chromodomain interaction with methylated $\mathrm{H} 3-\mathrm{K} 36$ links histone deacetylation to Pol II elongation. Mol Cell 2005, 20:97I-978.

61. Saleh A, Schieltz D, Ting N, McMahon SB, Litchfield DW, Yates JR 3rd, Lees-Miller SP, Cole MD, Brandl Cl: Tra Ip is a component of the yeast Ada.Spt transcriptional regulatory complexes. I Biol Chem 1998, 273:26559-26565.

62. Wapinski I, Pfeffer A, Friedman N, Regev A: Natural history and evolutionary principles of gene duplication in fungi. Nature 2007, 449:54-61.

63. Arevalo-Rodriguez M, Heitman J: Cyclophilin A is localized to the nucleus and controls meiosis in Saccharomyces cerevisiae. Eukaryot Cell 2005, 4: 17-29.

64. Mata J, Lyne R, Burns G, Bahler J: The transcriptional program of meiosis and sporulation in fission yeast. Nat Genet 2002, 32:143-147.

65. Lim CS, Mian IS, Dernburg AF, Campisi J: C. elegans clk-2, a gene that limits life span, encodes a telomere length regulator similar to yeast telomere binding protein Tel2p. Curr Biol 2001, I I:1706-1710.

66. Jiang N, Benard CY, Kebir H, Shoubridge EA, Hekimi S: Human CLK2 links cell cycle progression, apoptosis, and telomere length regulation. J Biol Chem 2003, 278:21678-2I684.

67. Kota RS, Runge KW: The yeast telomere length regulator TEL2 encodes a protein that binds to telomeric DNA. Nucleic Acids Res 1998, 26:1528-1535.

68. Runge KW, Zakian VA: TEL2, an essential gene required for telomere length regulation and telomere position effect in Saccharomyces cerevisiae. Mol Cell Biol 1996, 16:3094-3 105.

69. Hayashi T, Hatanaka M, Nagao K, Nakaseko Y, Kanoh J, Kokubu A Ebe M, Yanagida M: Rapamycin sensitivity of the Schizosaccharomyces pombe tor 2 mutant and organization of two highly phosphorylated TOR complexes by specific and common subunits. Genes Cells 2007, I 2:1357-1370.

70. Lee KK, Prochasson P, Florens L, Swanson SK, Washburn MP, Workman JL: Proteomic analysis of chromatin-modifying complexes in Saccharomyces cerevisiae identifies novel subunits. Biochem Soc Trans 2004, 32:899-903.

7I. Cairns BR, Erdjument-Bromage H, Tempst P, Winston F, Kornberg RD: Two actin-related proteins are shared functional components of the chromatin-remodeling complexes RSC and SWI/SNF. Mol Cell 1998, 2:639-65I.

72. Monahan BJ, Villen J, Marguerat S, Bahler J, Gygi SP, Winston F: Fission yeast SWIISNF and RSC complexes show compositional and functional differences from budding yeast. Nat Struct Mol Biol 2008, 15:873-880.

73. Wilson B, Erdjument-Bromage H, Tempst P, Cairns BR: The RSC chromatin remodeling complex bears an essential fungalspecific protein module with broad functional roles. Genetics 2006, I 72:795-809.

74. Shou W, Azzam R, Chen SL, Huddleston MJ, Baskerville C, Charbonneau H, Annan RS, Carr SA, Deshaies RJ: Cdc5 influences phosphorylation of NetI and disassembly of the RENT complex. BMC Mol Biol 2002, 3:3

75. Shou W, Seol JH, Shevchenko A, Baskerville C, Moazed D, Chen ZW, Jang J, Charbonneau H, Deshaies RJ: Exit from mitosis is triggered by Teml-dependent release of the protein phosphatase Cdc I 4 from nucleolar RENT complex. Cell 1999, 97:233-244.

76. Loewith R, Jacinto E, Wullschleger S, Lorberg A, Crespo JL, Bonenfant D, Oppliger W, Jenoe P, Hall MN: Two TOR complexes, only one of which is rapamycin sensitive, have distinct roles in cell growth control. Mol Cell 2002, 10:457-468.

77. Davey MJ, Indiani C, O'Donnell M: Reconstitution of the Mcm2$7 p$ heterohexamer, subunit arrangement, and ATP site architecture. J Biol Chem 2003, 278:449 I-4499.

78. Liu HY, Badarinarayana V, Audino DC, Rappsilber J, Mann M, Denis 
CL: The NOT proteins are part of the CCR4 transcriptional complex and affect gene expression both positively and negatively. EMBO J 1998, I 7:1096-I I06.

79. Valpuesta JM, Martin-Benito J, Gomez-Puertas P, Carrascosa JL, Willison KR: Structure and function of a protein folding machine: the eukaryotic cytosolic chaperonin CCT. FEBS Lett 2002, 529: I I- I6.

80. Gregan J, Riedel CG, Petronczki M, Cipak L, Rumpf C, Poser I, Buchholz $\mathrm{F}$, Mechtler K, Nasmyth K: Tandem affinity purification of functional TAP-tagged proteins from human cells. Nat Protoc 2007, 2:I|45-II5I.

8I. Doyon Y, Selleck W, Lane WS, Tan S, Cote J: Structural and functional conservation of the NuA4 histone acetyltransferase complex from yeast to humans. Mol Cell Biol 2004, 24:1884-1896.

82. Cai Y, Jin J, Tomomori-Sato C, Sato S, Sorokina I, Parmely TJ, Conaway RC, Conaway JW: Identification of new subunits of the multiprotein mammalian TRRAP/TIP60-containing histone acetyltransferase complex. J Biol Chem 2003, 278:42733-42736.

83. Ruhl DD, Jin J, Cai Y, Swanson S, Florens L, Washburn MP, Conaway RC, Conaway JW, Chrivia JC: Purification of a human SRCAP complex that remodels chromatin by incorporating the histone variant H2A.Z into nucleosomes. Biochemistry 2006 , 45:567I-5677

84. Li J, Wang J, Nawaz Z, Liu JM, Qin J, Wong J: Both corepressor proteins SMRT and N-CoR exist in large protein complexes containing HDAC3. EMBO J 2000, 19:4342-4350.

85. Yoon HG, Chan DW, Huang ZQ, Li J, Fondell JD, Qin J, Wong J: Purification and functional characterization of the human N-CoR complex: the roles of HDAC3, TBLI and TBLRI. EMBO J 2003, 22:1336-1346

86. Cai Y, Jin J, Florens L, Swanson SK, Kusch T, Li B, Workman JL, Washburn MP, Conaway RC, Conaway JW: The mammalian YLI protein is a shared subunit of the TRRAP/TIP60 histone acetyltransferase and SRCAP complexes. I Biol Chem 2005, 280: $13665-13670$

87. Fleischer TC, Yun UJ, Ayer DE: Identification and characterization of three new components of the mSin3A corepressor complex. Mol Cell Biol 2003, 23:3456-3467.

88. Yochum GS, Ayer DE: Role for the mortality factors MORF4, MRGX, and MRGI 5 in transcriptional repression via associations with PfI, mSin3A, and Transducin-Like Enhancer of Split. Mol Cell Biol 2002, 22:7868-7876.

89. Hakimi MA, Bochar DA, Chenoweth J, Lane WS, Mandel G, Shiekhat$\operatorname{tar} \mathrm{R}$ : A core-BRAF35 complex containing histone deacetylase mediates repression of neuronal-specific genes. Proc Natl Acad Sci USA 2002, 99:7420-7425.

90. Underhill C, Qutob MS, Yee SP, Torchia J: A novel nuclear receptor corepressor complex, N-CoR, contains components of the mammalian SWI/SNF complex and the corepressor KAP-I. J Biol Chem 2000, 275:40463-40470.

91. Jin J, Cai Y, Yao T, Gottschalk AJ, Florens L, Swanson SK, Gutierrez JL, Coleman MK, Workman JL, Mushegian A, Washburn MP, Conaway RC, Conaway JW: A mammalian chromatin remodeling complex with similarities to the yeast INO80 complex. J Biol Chem 2005, 280:4I207-4I2I2.

92. Bao $Y$, Shen $X$ : SnapShot: chromatin remodeling complexes. Cell 2007, I 29:632.

93. Wessel D, Flugge UI: A method for the quantitative recovery of protein in dilute solution in the presence of detergents and lipids. Anal Biochem 1984, I 38: |4|-|43.

94. Shevchenko A, Tomas H, Havlis J, Olsen JV, Mann M: In-gel digestion for mass spectrometric characterization of proteins and proteomes. Nat Protoc 2006, I:2856-2860.

95. Thomas H, Havlis J, Peychl J, Shevchenko A: Dried-droplet probe preparation on AnchorChip trade mark targets for navigating the acquisition of matrix-assisted laser desorption/ionization time-of-flight spectra by fluorescence of matrix/analyte crystals. Rapid Commun Mass Spectrom 2004, I 8:923-930.

96. Havlis J, Thomas H, Sebela M, Shevchenko A: Fast-response proteomics by accelerated in-gel digestion of proteins. Anal Chem 2003, 75: I 300-I306.

97. Shevchenko A, Chernushevich I, Wilm M, Mann M: " De novo " sequencing of peptides recovered from in-gel digested proteins by nanoelectrospray tandem mass spectrometry. Mol Biotechnol 2002, 20: 107-II8.

98. Altschul SF, Madden TL, Schaffer AA, Zhang J, Zhang Z, Miller W, Lipman DJ: Gapped BLAST and PSI-BLAST: a new generation of protein database search programs. Nucleic Acids Res 1997, 25:3389-3402.

99. Quevillon E, Silventoinen V, Pillai S, Harte N, Mulder N, Apweiler R, Lopez R: InterProScan: protein domains identifier. Nucleic Acids Res 2005, 33:WI I6-I20.

100. Roguev A, Krogan NJ: BAC to the future: functional genomics in mammals. Nat Methods 2008, 5:383-384.

I0I. Newman DR, Kuhn JF, Shanab GM, Maxwell ES: Box C/D snoRNAassociated proteins: two pairs of evolutionarily ancient proteins and possible links to replication and transcription. RNA 2000, 6:86I-879.

102. King TH, Decatur WA, Bertrand E, Maxwell ES, Fournier MJ: A wellconnected and conserved nucleoplasmic helicase is required for production of box C/D and H/ACA snoRNAs and localization of snoRNP proteins. Mol Cell Biol 200 I, 2 I:773 I-7746.

103. Vassilev A, Yamauchi J, Kotani T, Prives C, Avantaggiati ML, Qin J, Nakatani $Y$ : The $\mathbf{4 0 0} \mathrm{kDa}$ subunit of the PCAF histone acetylase complex belongs to the ATM superfamily. Mol Cell I998, 2:869-875.

104. Cai Y, Jin J, Florens L, Swanson SK, Kusch T, Li B, Workman JL, Washburn MP, Conaway RC, Conaway JW: The mammalian YLI protein is a shared subunit of the TRRAP/TIP60 histone acetyltransferase and SRCAP complexes. I Biol Chem 2005, 280: 13665-13670.

105. Mazumdar A, Wang RA, Mishra SK, Adam L, Bagheri-Yarmand R, Mandal M, Vadlamudi RK, Kumar R: Transcriptional repression of oestrogen receptor by metastasis-associated protein I corepressor. Nat Cell Biol 200I, 3:30-37.

106. Shi Y], Matson C, Lan F, Iwase S, Baba T, Shi Y: Regulation of LSD I histone demethylase activity by its associated factors. Mol Cell 2005, 19:857-864.

107. Viiri KM, Korkeamaki H, Kukkonen MK, Nieminen LK, Lindfors K, Peterson P, Maki M, Kainulainen H, Lohi O: SAP30L interacts with members of the Sin3A corepressor complex and targets Sin3A to the nucleolus. Nucleic Acids Res 2006, 34:3288-3298.

108. Humphrey GW, Wang Y, Russanova VR, Hirai T, Qin J, Nakatani Y, Howard $\mathrm{BH}$ : Stable histone deacetylase complexes distinguished by the presence of SANT domain proteins CoREST/ kiaa007 I and Mta-LI. J Biol Chem 200I, 276:68I 7-6824. 